\title{
A review of $\mathrm{CoSb}_{3}$-based skutterudite thermoelectric materials
}

\author{
Zhi-Yuan LIU ${ }^{a, b,}$, Jiang-Long ZHU ${ }^{a, b}$, Xin TONG ${ }^{a, b}$, Shuo NIU ${ }^{a, b}$, Wen-Yu ZHAO ${ }^{c,{ }^{*}}$ \\ ${ }^{a}$ School of Materials Science and Engineering, Anhui University of Technology, Maanshan 243002, China \\ ${ }^{b}$ Key Laboratory of Green Fabrication and Surface Technology of Advanced Metal Materials, \\ Ministry of Education, Anhui University of Technology, Maanshan 243002, China \\ ${ }^{c}$ State Key Laboratory of Advanced Technology for Materials Synthesis and Processing, \\ Wuhan University of Technology, Wuhan 430070, China
}

Received: March 14, 2020; Revised: June 2, 2020; Accepted: July 13, 2020

(C) The Author(s) 2020.

\begin{abstract}
The binary skutterudite $\mathrm{CoSb}_{3}$ is a narrow bandgap semiconductor thermoelectric (TE) material with a relatively flat band structure and excellent electrical performance. However, thermal conductivity is very high because of the covalent bond between $\mathrm{Co}$ and $\mathrm{Sb}$, resulting in a very low $Z T$ value. Therefore, researchers have been trying to reduce its thermal conductivity by the different optimization methods. In addition, the synergistic optimization of the electrical and thermal transport parameters is also a key to improve the $Z T$ value of $\mathrm{CoSb}_{3}$ material because the electrical and thermal transport parameters of TE materials are closely related to each other by the band structure and scattering mechanism. This review summarizes the main research progress in recent years to reduce the thermal conductivity of $\mathrm{CoSb}_{3}$-based materials at atomic-molecular scale and nano-mesoscopic scale. We also provide a simple summary of achievements made in recent studies on the non-equilibrium preparation technologies of $\mathrm{CoSb}_{3}$-based materials and synergistic optimization of the electrical and thermal transport parameters. In addition, the research progress of $\mathrm{CoSb}_{3}$-based TE devices in recent years is also briefly discussed.
\end{abstract}

Keywords: skutterudite; $\mathrm{CoSb}_{3}$-based materials; lattice thermal conductivity; synergistic optimization; thermoelectric properties; thermoelectric devices

\section{Introduction}

Thermoelectric (TE) materials can directly convert thermal energy to electrical energy, which have attracted wide attention due to their fascinating applications in power generation and refrigeration [1-4]. The performance of TE materials is characterized by the dimensionless figure of merit $Z T\left(Z T=\sigma \alpha^{2} T / \kappa\right)$, which

\footnotetext{
* Corresponding authors.

E-mail: Z.-Y. Liu, zhiyuanliu826@163.com;

W.-Y.Zhao,wyzhao@whut.edu.cn
}

is mainly determined by the Seebeck coefficient $(\alpha)$, electrical conductivity $(\sigma)$, and thermal conductivity $(\kappa)$, where $T$ is the absolute temperature, and $\sigma \alpha^{2}$ is the power factor. $\alpha$ and $\sigma$ are decided by the electronic structure and carrier transport properties (Hall coefficient $R_{\mathrm{H}}$, carrier concentration $n$, carrier mobility $\mu_{\mathrm{H}}$ ), which are used to characterize the electrical transport properties of the material. $\kappa$ is the thermal conductivity written as the sum of electronic $\left(\kappa_{\mathrm{E}}\right)$ and lattice $\left(\kappa_{\mathrm{L}}\right)$ components, which is used to characterize the thermal transport properties of the material. High $\sigma \alpha^{2}$ and low $\kappa$ are required to obtain high $Z T$. However, these parameters 
are closely related to each other and mutually constrained by the band structure and the scattering mechanism. Therefore, it is very difficult to decouple the electrical and thermal performance parameters. The $\kappa_{\mathrm{E}}$ is closely related to the $\sigma$ according to the Wiedemann-Franz law $\kappa_{\mathrm{E}}=L \sigma T$, while the $\kappa_{\mathrm{L}}$ is less related to the electrical transport properties. Therefore, researchers initially used various optimization methods to reduce the $\kappa_{\mathrm{L}}$ of materials, which is a very effective way to improve the $Z T$ values. The $\kappa_{\mathrm{L}}$ of TE materials has been significantly reduced by alloying, element filling, the introduction of nanoscale second-phase, nano-interface or nanopore, copper ion-like behavior, and anharmonic phonon coupling [5-12]. It can even be reduced to near the theoretical minimum [7]. The electrical transport properties of TE materials can be also effectively increased by energy band engineering, such as high energy valley degeneracy or energy band convergence, resonance energy level, Peierls distortion, electron orbit hybridization, energy filtering, multi-band optimization, and optimized bandwidth [13-20]. In recent years, the key to further improve the $Z T$ value is to decouple the interrelated electrical and thermal transport parameters by the magnetic nanocomposite [21,22], all-scale hierarchical structuring, endotaxial nanostructuring and valence-band offset engineering, and hierarchical compositionally alloyed nanostructures [23-27]. According to the applicable temperature of TE materials, it can be divided into low-, medium-, and high-temperature TE materials. Skutterudite is recognized as the most promising TE material in the mid-temperature range due to its excellent electrical transport properties. Some research progresses [4,28-30] about skutterudite materials have been systematically reviewed in recent years. However, research progresses on how to reduce the thermal conductivity of $\mathrm{CoSb}_{3}$-based TE materials at atomic-molecular scale and nano-mesoscopic scale, and how to optimize synergistically the electrical and thermal transport properties, are rarely reported.

Figure 1(a) shows the energy band structure of binary $\mathrm{CoSb}_{3}$ TE material [31-34]. It can be seen that it is a narrow bandgap semiconductor material with a band gap of about $0.22 \mathrm{eV}$. Therefore, it has a large carrier concentration and electrical conductivity. In addition, $\mathrm{CoSb}_{3}$ has a large carrier effective mass and Seebeck coefficient because of its flat energy band. However, the thermal conductivity of $\mathrm{CoSb}_{3}$ is very high due to the covalent bond between $\mathrm{Co}$ and $\mathrm{Sb}$ (see Fig. 1(b)), resulting in a very low $Z T$ value. Therefore,

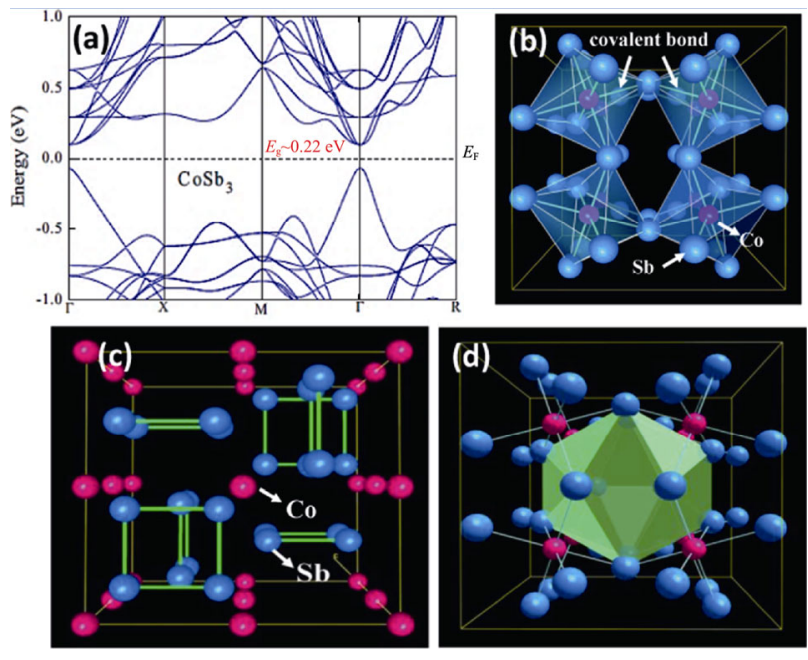

Fig. 1 (a) Band structure (reproduced with permission from Ref. [31], (C) American Physical Society 2008) and (b-d) crystal structure of $\mathrm{CoSb}_{3}$.

it has become the focus by reducing the thermal conductivity without deteriorating the electrical properties of the $\mathrm{CoSb}_{3}$ material. As we mentioned above, the lattice component in thermal conductivity is independent of the electrical transport performance. Therefore, reducing lattice thermal conductivity by enhancing phonon scattering without causing significant changes in $\sigma$ and $\alpha$ becomes a very effective way to increase the $Z T$ value of $\mathrm{CoSb}_{3}$ TE materials. In addition, some advanced preparation processes can also achieve the purposes of reducing the $\kappa_{\mathrm{L}}$ and increasing $Z T$ value.

In this review, the main research progresses on how to reduce the thermal conductivity of $\mathrm{CoSb}_{3}$-based materials at atomic-molecular and nano-mesoscopic scale in recent years were summarized. A simple summary of achievements made in recent studies on the non-equilibrium preparation technologies of $\mathrm{CoSb}_{3}$-based materials and synergistic optimization of the electrical and thermal transport parameters was also provided. In addition, the investigations related to fabricating $\mathrm{CoSb}_{3}$-based TE device have garnered a lot of attention in recent years. Therefore, we also briefly summarize the research progresses of $\mathrm{CoSb}_{3}$-based TE devices in recent years.

\section{Optimization of the thermal performance}

$\mathrm{CoSb}_{3}$ material has better electrical transport properties based on its band structure. However, thermal conductivity of $\mathrm{CoSb}_{3}$ is very high due to the covalent bond between 
$\mathrm{Co}$ and $\mathrm{Sb}$ (see Fig. 1(b)), resulting in a very low $Z T$ value (only about 0.1 ). The $\kappa_{\mathrm{L}}$ of the single crystal $\mathrm{CoSb}_{3}$ material at room temperature prepared by the Bridgman method is up to $10 \mathrm{~W} \cdot \mathrm{m}^{-1} \cdot \mathrm{K}^{-1}$ [35]. Therefore, how to reduce the $\kappa_{\mathrm{L}}$ of $\mathrm{CoSb}_{3}$ material is the key to improve the TE performance. The decrease of $\kappa_{\mathrm{L}}$ is mainly achieved at the atomic-molecular scale and the nano-mesoscopic scale.

\section{1 Optimization at atomic-molecular scale}

There are two main ways to reduce the $\kappa_{\mathrm{L}}$ of $\mathrm{CoSb}_{3}$-based materials at the atomic-molecular scale: (i) forming solid solution alloy by doping; (ii) introducing other atoms into the $\mathrm{Sb}_{12}$ icosahedral void of $\mathrm{CoSb}_{3}$ to form the filled skutterudites.

Forming solid solution alloy by doping. As early as the 1950s, Ioffe and Ioffe [36] proposed that the formation of solid solution alloys by doping can effectively reduce the $\kappa_{\mathrm{L}}$ of materials. The cations (or anions) in the crystal structure of $\mathrm{CoSb}_{3}$ can be partially replaced by similar atoms at $\mathrm{Co}$ or $\mathrm{Sb}$ site to form ternary or multicomponent solid solutions. The $\kappa_{\mathrm{L}}$ of solid solution formed by partial substitution is significantly decreased. This is mainly due to the existence of high concentration point defects in solid solution. A large number of point defects can significantly scatter phonons, thereby reducing the lattice thermal conductivity. These point defects mainly come from the fluctuations of mass and strain fields because of the difference of the mass and radius between the foreign atom and the guest atom. In the solid solution, the point defects caused by doping will lead to lattice distortion and strong phonon-phonon, free electron-phonon coupling based on the polaron theory [37-40]. Therefore, it is possible that the polaron theory can also effectively explain the decrease of $\kappa_{\mathrm{L}}$ caused by point defects.

In addition, Callaway [41] proposed a phenomenological model for the calculation of $\kappa_{\mathrm{L}}$. A simplified version of Callaway model is given in Eq. (1):

$$
\kappa_{\mathrm{L}}=\frac{4 \pi k_{\mathrm{B}}}{v}\left(\frac{k_{\mathrm{B}} T}{h}\right)^{3} \int_{0}^{\theta_{\mathrm{D}} / T} \frac{x^{4} \mathrm{e}^{x}}{\tau^{-1}\left(\mathrm{e}^{x}-1\right)} \mathrm{d} x
$$

where $x=h \bar{\omega} / 4 \pi k_{\mathrm{B}} T$ ( $\omega$ is the phonon frequency, $k_{\mathrm{B}}$ is the Boltzmann constant), $v$ is the phonon velocity, and $\theta_{\mathrm{D}}$ is the Debye temperature, $h$ is the Planck constant, $\tau$ is the effective relaxation time, and $\tau$ can be expressed by the following Eqs. (2)-(7) [41-47]:

$$
\begin{gathered}
\tau^{-1}=\frac{V}{4 \pi v^{3}}\left(\Gamma_{\mathrm{B}}+\Gamma_{\mathrm{S}}\right) \bar{\omega}^{4} \\
+\frac{\gamma^{2} h}{2 \pi M v^{2} \theta_{\mathrm{D}}} \bar{\omega}^{2} T \exp \left(-\theta_{\mathrm{D}} / 3 T\right)+C \bar{\omega}+v / d \\
\tau^{-1}=\tau_{\mathrm{PD}}^{-1}+\tau_{\mathrm{U}}^{-1}+\tau_{\mathrm{PE}}^{-1}+\tau_{\mathrm{B}}^{-1} \\
\tau_{\mathrm{PD}}^{-1}=\frac{V}{4 \pi v^{3}}\left(\Gamma_{\mathrm{B}}+\Gamma_{\mathrm{S}}\right) \bar{\omega}^{4} \\
\tau_{\mathrm{U}}^{-1}=\frac{\gamma^{2} h}{2 \pi M v^{2} \theta_{\mathrm{D}}} \bar{\omega}^{2} T \exp \left(-\theta_{\mathrm{D}} / 3 T\right) \\
\tau_{\mathrm{PE}}^{-1}=\frac{E_{\mathrm{def}}^{2} m^{* 2}}{4 \pi^{2} h^{3} \rho v_{1}} \bar{\omega} \\
\tau_{\mathrm{B}}^{-1}=v / d
\end{gathered}
$$

where $\tau_{\mathrm{PD}}$ is the effective relaxation time caused by scattering of point defects, $\tau_{U}$ is the effective relaxation time caused by phonon-phonon U-scattering, $\tau_{\mathrm{PE}}$ is the effective relaxation time caused by free electron-phonon scattering, $\tau_{\mathrm{B}}$ is the effective relaxation time caused by grain boundary scattering, $d$ is the average grain size, $\Gamma_{\mathrm{B}}$ and $\Gamma_{\mathrm{S}}$ are the disorder scattering parameters due to mass and strain field fluctuations, respectively. $\gamma$ is the Grueneisen parameter, which strongly depends on the anharmonicity of the bonding, and is given as $\gamma=\left(3 \beta B_{\mathrm{m}} V_{\mathrm{m}}\right) / C_{\mathrm{v}}$, where $\beta, V_{\mathrm{m}}, B_{\mathrm{m}}$, $C_{\mathrm{v}}$ are the linear thermal expansion coefficient, molar volume, isothermal bulk modulus, and heat capacity, respectively. $E_{\text {def }}$ is the deformed potential of conduction band, which is related to the strength of electron lattice interaction, $m^{*}$ is the carrier effective mass, $\rho$ is the density, and $v_{1}$ is the phonon longitudinal velocity.

Based on the Callaway model and the effective relaxation time caused by different types of scattering, the $\kappa_{\mathrm{L}}$ of materials is closely related to point defect scattering, phonon-phonon, free electron-phonon, and boundary scattering, which all significantly affect the $\kappa_{\mathrm{L}}$ of materials. Similarly, in solid solution materials, the scattering of point defects, phonon-phonon scattering, and free electron-phonon scattering caused by mass and strain field fluctuations can significantly reduce the $\kappa_{\mathrm{L}}$, which is consistent with the results of polaron theory.

Figure 2 shows the timeline of room-temperature $\kappa_{\mathrm{T}}$ and $\kappa_{\mathrm{L}}$ for several typical $\mathrm{CoSb}_{3}$-based solid solution alloy materials. It can be seen that the room-temperature $\kappa_{\mathrm{T}}$ and $\kappa_{\mathrm{L}}$ of the $\mathrm{CoSb}_{3}$-based solid solution alloy formed by doping are greatly reduced compared to that of the 


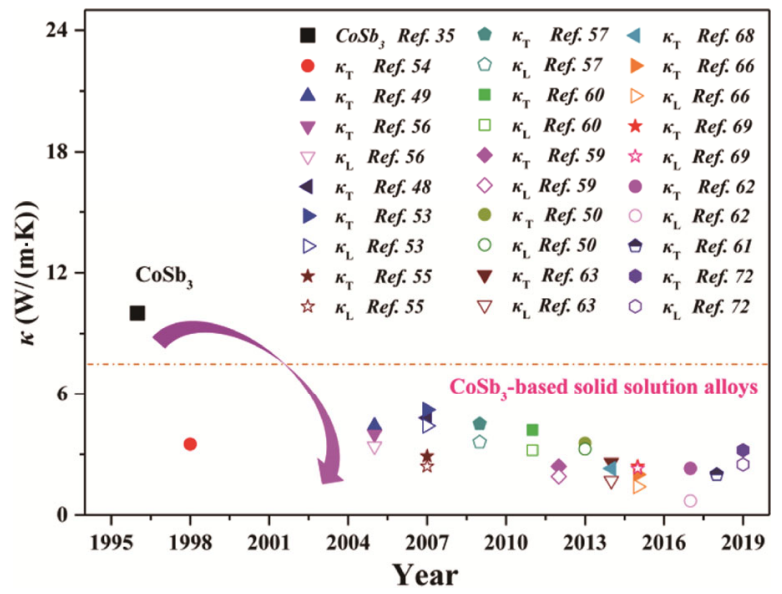

Fig. 2 Timeline of room-temperature thermal conductivity $\left(\kappa_{\mathrm{T}}\right)$ and lattice thermal conductivity $\left(\kappa_{\mathrm{L}}\right)$ for several typical $\mathrm{CoSb}_{3}$-based solid solution alloy materials.

binary $\mathrm{CoSb}_{3}$ material. The solid solution of $\mathrm{CoSb}_{3}$ is mainly obtained by substitution of atoms of the same and different families in periodic table of elements [5,48-65]. The $\kappa_{\mathrm{L}}$ of the formed solid solution by the partial substitution with the isoelectronic atoms has an obvious decrease because of the increase in point defects induced by the big difference between atomic radius and mass between guest atoms and host atoms. Zhou et al. [49] reported that a large number of point defects in the ternary $\mathrm{CoSb}_{3}$-based solid solution formed by substituting $\mathrm{Sb}$ with As could strongly scatter the phonons, which effectively reduced the $\kappa_{\mathrm{L}}$. In addition to increasing point defects to reduce the $\kappa_{\mathrm{L}}$, the solid solution formed by partial substitution with non-isoelectronic heteroatom can also be used as donor doping to regulate the carrier concentration. In the Te-doped $\mathrm{CoSb}_{3}$-based ternary solid solution alloy, Te provides a large amount of electrons as a donor when Te replaces $\mathrm{Sb}$, causing the Fermi level of the $\mathrm{CoSb}_{3}$ to rise, which significantly improves the electrical conductivity. At the same time, the point defects in the solid solution enhance the phonon scattering when $\mathrm{Sb}$ is partially substituted with Te, resulting in the remarkable decrease of the $\kappa_{\mathrm{L}}$. Te-doped ternary alloy $\mathrm{CoSb}_{3-x} \mathrm{Te}_{x}$ prepared by Liu et $a l$. [5] has a high $Z T$ value of 0.93 at $800 \mathrm{~K}$. In addition, the single doped atoms have the problem of solid solubility limit because of the existence of the size and charge difference between atoms. In particular, some atoms have a lower solid solution quantity in $\mathrm{CoSb}_{3}$. Therefore, researchers try to form multi-component solid solution by multi-element doping to further improve the solid solution limit and reduce the $\kappa_{\mathrm{L}}$ [58]. Su et al. $[59,60]$ reported that Te doping limit was significantly increased for the quaternary compound $\mathrm{CoSb}_{3-x-y} \mathrm{Ge}_{y} \mathrm{Te}_{x}$ formed by Ge-doped $\mathrm{CoSb}_{3-x} \mathrm{Te}_{x}$ with the charge compensation of Ge. The presence of the group IV Ge compensates for the charge of the group VI Te, in turn, increases the solubility (doping limit) of Te. For Ge and Te co-doped skutterudite $\mathrm{CoSb}_{3-x-y} \mathrm{Ge}_{y} \mathrm{Te}_{x}$, the solid solubility of $\mathrm{Te}$ on the $\mathrm{Sb}$ site is higher than that of single-doped Te due to partial charge compensation by $\mathrm{Ge}$. The valence electron numbers of $\mathrm{Ge}, \mathrm{Sb}$, and $\mathrm{Te}$ are 4,5 , and 6 , respectively. A Ge atom substituting for $\mathrm{Sb}$ on the $\left[\mathrm{Sb}_{4}\right]^{4-}$ rings compensates for the charge of $\mathrm{Te}$ substituted for $\mathrm{Sb}$ on the same $\left[\mathrm{Sb}_{4}\right]^{4-}$ rings and effectively increases the solubility of $\mathrm{Te}$ in $\mathrm{CoSb}_{3}$ [60]. In addition to the phonon point-defect scattering induced by the co-doping of $\mathrm{Ge}$ and $\mathrm{Te}$, the nanostructures formed in situ may also contribute to the decrease of lattice thermal conductivity. As a result, maximum $Z T$ value of the quaternary compound $\mathrm{CoSb}_{3-x-y} \mathrm{Ge}_{y} \mathrm{Te}_{x}$ reached 1.1 at $800 \mathrm{~K}$. In recent years, nanostructured $\mathrm{CoSb}_{3}$-based solid solution alloys have also been formed by some synthetic methods (such as high temperature and high pressure synthesis [66-70], plasma pulse sintering [71], magnesium reduction method [72], and microwave synthesis [73]). The $\kappa_{\mathrm{L}}$ of the $\mathrm{CoSb}_{3}$-based solid solution alloys prepared by these synthetic methods is significantly reduced, resulting in great increase of the $Z T$ value.

Introducing the filling atom. The most interesting feature of the crystal structure for $\mathrm{CoSb}_{3}$ material is that there are two intrinsic voids $\left(\mathrm{Sb}_{12}\right.$ icosahedron composed of twelve $\mathrm{Sb}$ atoms) occupying 2a position in the crystal lattice, as shown in Fig. 1(d). In the past 20 years, electropositive elements (such as alkali metals, alkaline earth metals, and rare earth metals) [34,74-107] or electronegativity elements (such as $\mathrm{S}, \mathrm{Se}, \mathrm{Br}$, and $\mathrm{Cl}$ ) [108-111] have been filled into the larger $\mathrm{Sb}_{12}$ icosahedral void to form filled skutterudite $\mathrm{R}_{x} \mathrm{Co}_{4} \mathrm{Sb}_{12}$ ( $\mathrm{R}$ for filled atom). A large number of studies found that the filling degree and filling amount of different kinds of filling atoms are different, and there is a problem of the upper limit of the filling amount. Shi et al. [112] predicted theoretically the upper limit of the filling amount of a series of filled atoms for filled skutterudites and proposed a simple electronegativity selection rule for the stability of $\mathrm{CoSb}_{3}$, that is $x_{\mathrm{Sb}}-x_{\mathrm{R}}>$ 0.80 . In other words, the electronegativity difference between $\mathrm{Sb}$ atom and filled atom $\mathrm{R}$ must be greater than 0.80 to form a stable filled skutterudite compound. Filled atoms that satisfy the principle of electronegativity 
proposed by Shi et al. is generally electropositive element, such as alkaline earth metals, alkali metals, and rare earth elements. The filled atoms act as a rattling center in the skutterudite void [113] and can strongly scatter the lattice phonons, causing a significant decrease in the $\kappa_{\mathrm{L}}$. In addition, the filled atoms can also serve as the donor atom to effectively adjust the carrier concentration because the donor atom has different electronegativity from the framework atom $\mathrm{Sb}$, which is more electronegative than the donor atom. Therefore, the introduction of filled atoms can improve significantly the TE transport properties of $\mathrm{CoSb}_{3}$ material.

The earliest research on filled skutterudites can be traced back to 1977. Jeitschko and Braun [114] first filled the lanthanide metal atoms (also called rare earth metal atoms) into the icosahedral voids of skutterudite, and prepared a series of filled skutterudite TE materials. Then in 1995, Slack [115] proposed a concept of "phonon-glass electron-crystal" (PGEC), that is, a good TE material should have the same excellent electrical properties as a crystalline material and a low thermal conductivity like a glass material. It is also proposed that the filled skutterudite meets the characteristics of PGEC. Sales et al. [6] first reported the $\mathrm{MFe}_{4-x} \mathrm{Co}_{x} \mathrm{Sb}_{12}$ $(\mathrm{M}=\mathrm{La}, \mathrm{Ce})$ filled skutterudite materials and studied the electrical and thermal transport properties in 1996. It was experimentally confirmed that the filled skutterudite materials have the transport properties of PGEC. Since then, the study of filled skutterudite materials has entered a research climax.

Although the TE performance of $\mathrm{CoSb}_{3}$ has been greatly improved by the single atom filling [34,74,75, $82,84,86,88,90-103]$, the TE properties of single-filled $\mathrm{CoSb}_{3}$ skutterudites can be further improved by doping other elements at Co or Sb sites [111,116,117]. Recently, Trivedi et al. [117] found that the $Z T$ value of single element Dy-filled $\mathrm{CoSb}_{3}$ skutterudites can be significantly enhanced by the microstructure and doping effect of $\mathrm{Ni}$. The $\mathrm{Dy}_{0.4} \mathrm{Co}_{3.2} \mathrm{Ni}_{0.8} \mathrm{Sb}_{12}$ material has a high $Z T$ value of up to 1.4 at $773 \mathrm{~K}$. To further reduce the $\kappa_{\mathrm{L}}$, the research on the filled skutterudite TE material system has gradually developed from single- to multiple-filled [118]. Theoretical and experimental results showed that multiple atomic filling can reduce the $\kappa_{\mathrm{L}}$ more effectively than single atom filling. The $Z T$ value of the filled $\mathrm{CoSb}_{3}$-based material was increased from about 1.0 for single filling [74] to about 2.0 for the multiple filling [7,87]. The $Z T$ values of these n-type filled $\mathrm{CoSb}_{3}$-based materials are obviously better than that of p-type $\mathrm{Fe}_{4} \mathrm{Sb}_{12}$-based skutterudite materials [119-121]. Zhao et al. [77] found that there was a 5p orbital coupling between the filled atom $\mathrm{In}$ and $\mathrm{Sb}$ in the n-type multiple-filled $\mathrm{CoSb}_{3}$ TE materials. The symmetry of $\mathrm{Sb}_{4}$ ring (Fig. 1(c)) in the $\mathrm{CoSb}_{3}$ structure was significantly improved, resulting in the remarkable enhancement in TE transport properties for the filled $\mathrm{CoSb}_{3}$ materials, as shown in Figs. 3(a) and 3(b). The multiple-filled skutterudite TE material $\mathrm{Ba}_{u} \mathrm{La}_{v} \mathrm{Yb}_{w} \mathrm{Co}_{4} \mathrm{Sb}_{12}$ prepared by Shi et al. [7] has a high $Z T$ value of 1.7 at $850 \mathrm{~K}$ (Fig. 3(e)). The high $Z T$ value benefits from the following two aspects: (i) controlling the filling fraction of multiple filled atoms to optimize the carrier concentration, leading to a higher power factor, as shown in Fig. 3(d); (ii) strong scattering of wide-band phonons can be achieved by different rattling frequencies of the multiple atomic filling in the icosahedral voids of $\mathrm{CoSb}_{3}$ TE material, making the $\kappa_{\mathrm{L}}$ close to the theoretical minimum (Fig. 3(d)). Filling atoms that satisfy the principle of electronegativity selection proposed by Shi et al. [112] are generally electropositive element. It has rarely been reported that the stable filled skutterudite compounds can be formed by using electronegative elements (such as $\mathrm{S}, \mathrm{Se}, \mathrm{Br}, \mathrm{Cl}$, etc.) as filler. Duan et al. [108] reported that elements with negative charge can be filled into the icosahedral voids of $\mathrm{CoSb}_{3}$ by certain charge compensation, forming the stable filled skutterudite compounds (Fig. 4). The filling of negatively charged elements can cause strong covalent interactions between guest and host atoms, and significantly lower $\kappa_{\mathrm{L}}$ by a unique "cluster vibration" characteristic as shown in Figs. 4(a)-4(c). The n-type $\mathrm{S}_{0.26} \mathrm{Co}_{4} \mathrm{Sb}_{11.11} \mathrm{Te}_{0.73}$ filled skutterudite material has a high $Z T$ value of up to 1.5 at $850 \mathrm{~K}$. Figure 5 shows the timeline of $Z T$ for several typical $\mathrm{CoSb}_{3}$-based filled skutterudite TE materials in recent 20 years. It can be seen that the $Z T_{\max }$ value of the $\mathrm{CoSb}_{3}$-based TE materials is between 1.0 and 2.0, which is significantly improved compared with that of the binary $\mathrm{CoSb}_{3}$. Therefore, introducing foreign atoms into the intrinsic icosahedral void is a very effective way to improve significantly the TE properties of the $\mathrm{CoSb}_{3}$ TE materials.

\section{2 Optimization at nano-mesoscopic scale}

Low dimensional CoSb $\boldsymbol{C}_{3}$-based materials. The lowdimensionalization of the material structure can cause significant changes in the electrical and thermal transport properties of the material. The changes of electrical transport properties are reflected mainly in the increase 
(a)

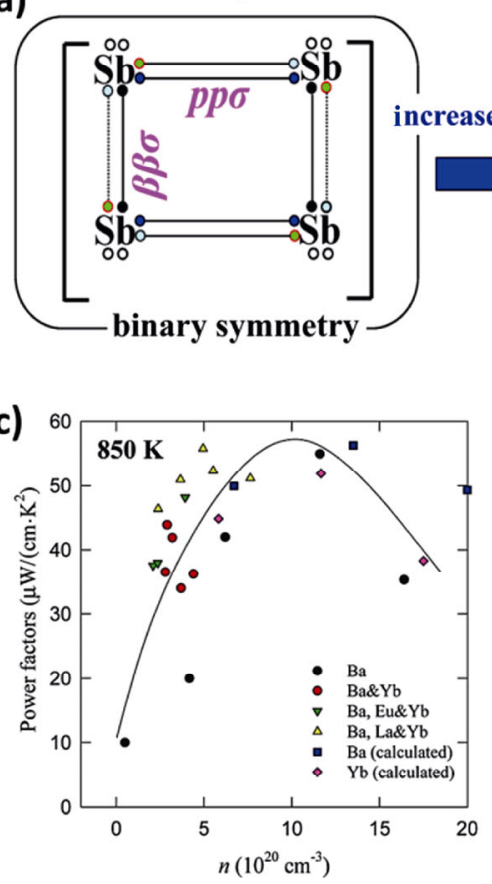

$\mathrm{Ba}_{r} \mathrm{In}_{s} \mathrm{Co}_{4} \mathrm{Sb}_{12}$

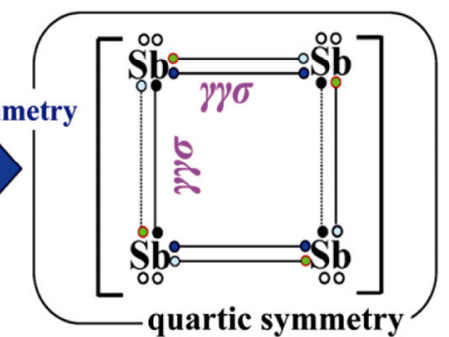

(d)

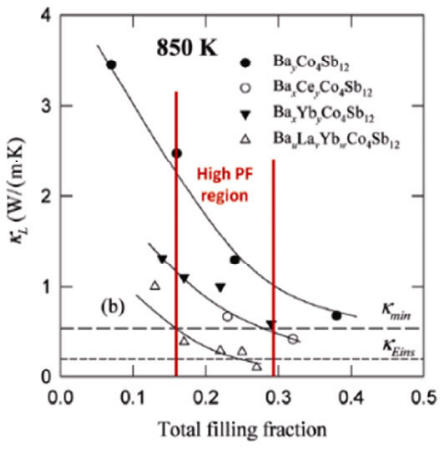

(b)

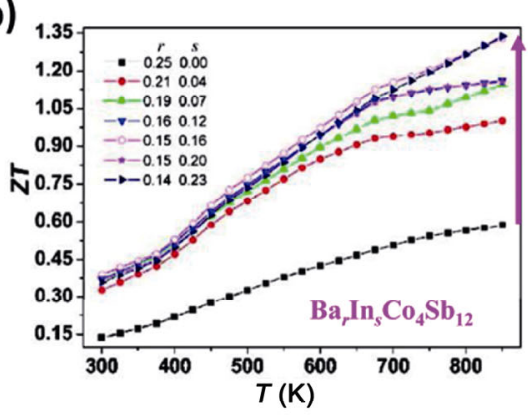

(e)

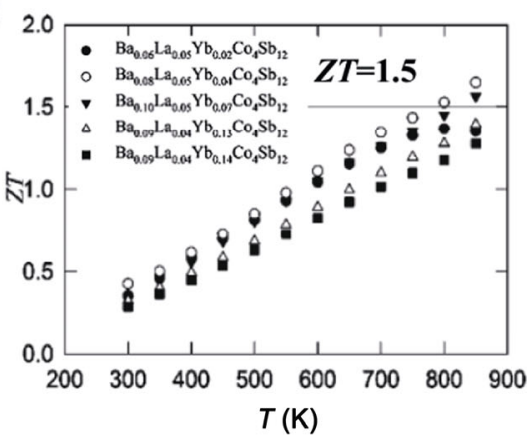

Fig. 3 (a) Improvement of symmetry of the rectangular $\mathrm{Sb}_{4}$ ring for $\mathrm{n}$-type $\mathrm{Ba}_{r} \mathrm{In}_{s} \mathrm{Co}_{4} \mathrm{Sb}_{12}$ materials induced by the $5 \mathrm{p}$ orbital hybridization between the filler In and $\mathrm{Sb}$; (b) temperature dependence of $Z T$ values for $\mathrm{Ba}_{r} \mathrm{In}_{s} \mathrm{Co}_{4} \mathrm{Sb}_{12}$ materials. Reproduced with permission from Ref. [77], (C) American Chemical Society 2009. (c) Power factors at $850 \mathrm{~K}$ as a function of room-temperature carrier density for single-, double-, and multiple-filled skutterudites, and the solid line shows a trend for both the calculated and measured data; (d) high-temperature $(850 \mathrm{~K})$ lattice thermal conductivity as a function of total filling fraction; (e) temperature dependence of $Z T$ for $\mathrm{Ba}_{u} \mathrm{La}_{v} \mathrm{Yb}_{w} \mathrm{Co}_{4} \mathrm{Sb}_{12}$ multiple-filled skutterudites. Reproduced with permission from Ref. [7], (C) American Chemical Society 2011.

(a)
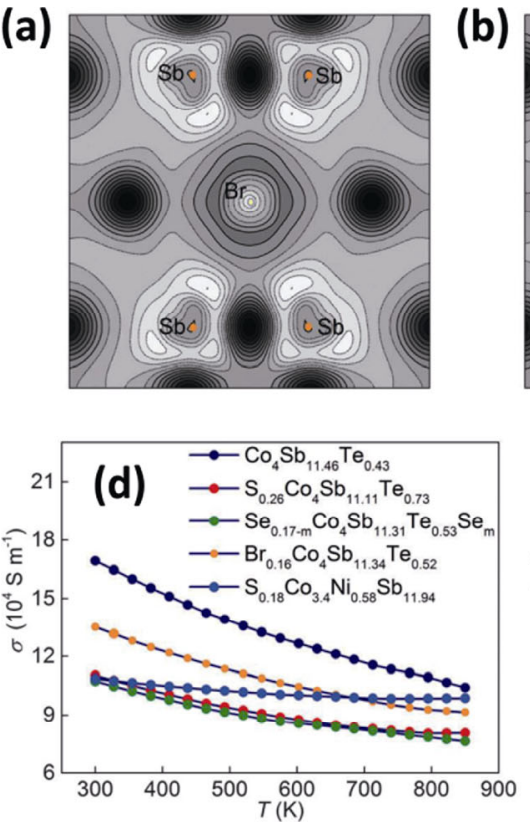

(b)

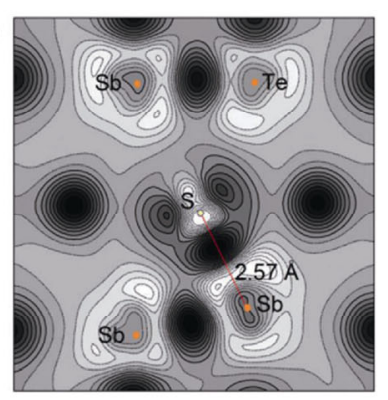

(c)
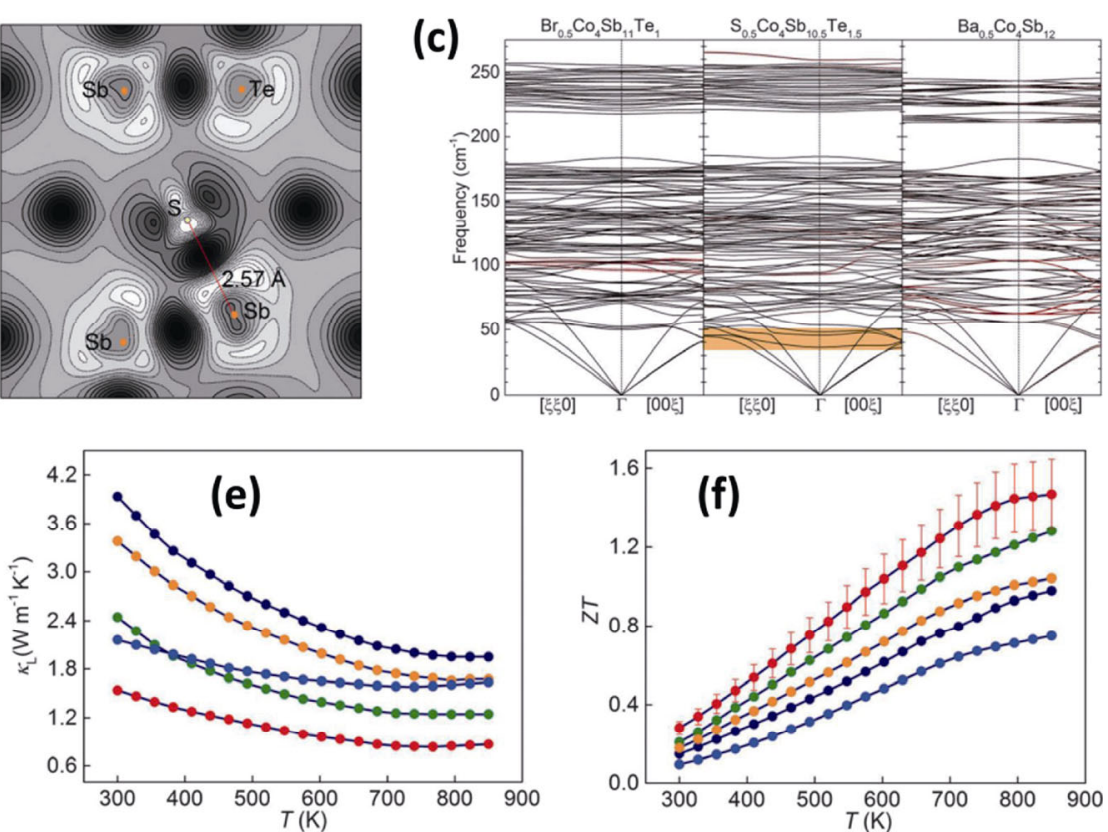

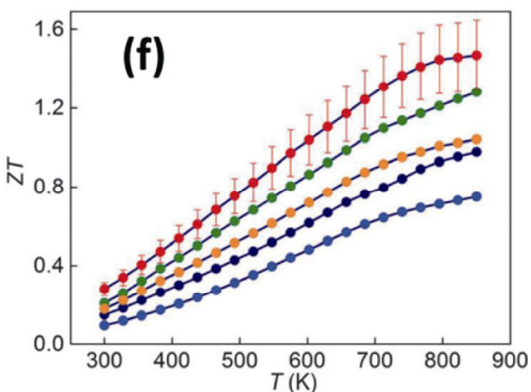

Fig. $4 \mathrm{CoSb}_{3}$ skutterudite TE materials with the electronegative guests. Calculated charge density difference at Sb four-ring plane in (a) $\mathrm{Br}_{0.063} \mathrm{Co}_{4} \mathrm{Sb}_{12}$ and (b) $\mathrm{S}_{0.063} \mathrm{Co}_{4} \mathrm{Sb}_{11.5} \mathrm{Te}_{0.5}$; (c) phonon spectra in filled skutterudites with electronegative guests. Temperature dependence of (d) electrical conductivity, (e) lattice thermal conductivity $\kappa_{\mathrm{L}}$, and (f) dimensionless figure of merit $Z T$ for the electronegative guest filled $\mathrm{CoSb}_{3}$ skutterudite materials. Reproduced with permission from Ref. [108], (C) The Royal Society of Chemistry 2016. 


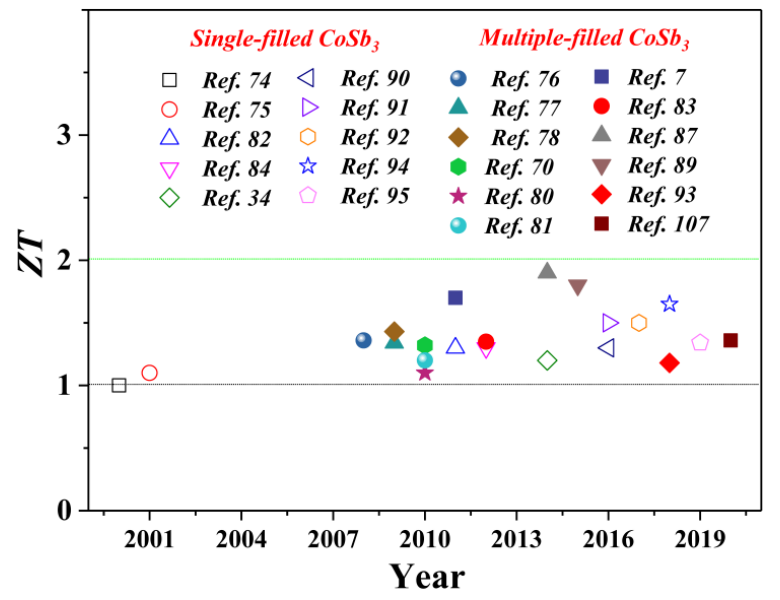

Fig. 5 Timeline of $Z T$ for several typical $\mathrm{CoSb}_{3}$-based filled skutterudites TE materials.

of the $\alpha$. The increase in $\alpha$ is mainly attributed to the increase in the density of electronic states near Fermi energy [122] induced by the quantum confinement effect after the low-dimensionalization [123], as shown in Fig. 6. The changes of thermal transport properties after the low-dimensionalization are reflected in the decrease in the $\kappa$. The decrease in $\kappa$ is mainly due to the fact that the high-density nano-interfaces in the low
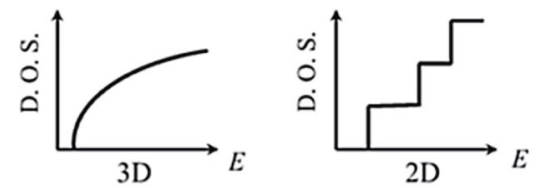

Bulk Semiconductor

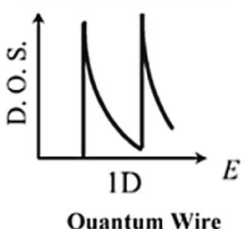

Quantum Well

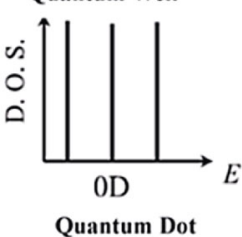

Fig. 6 Electronic density of states of different dimensions. Reproduced with permission from Ref. [122], (C) WILEYVCH Verlag GmbH \& Co. KGaA, Weinheim 2007.

dimensional materials enhance significantly the scattering of electrons and phonons. In the past ten years, TE properties of $\mathrm{CoSb}_{3}$ materials have been improved significantly by the nanocrystallization of $\mathrm{CoSb}_{3}$-based materials [124-140] or the preparation of thin film materials [141-147]. Toprak et al. [125] reported a novel chemical alloying method to prepare $\mathrm{CoSb}_{3}$ materials with different nanoparticle sizes. This novel chemical alloying method (or solution chemistry route) from a thermodynamic modelling [148-150] of the equilibria

Table 1 Room-temperature thermal conductivity $\left(\kappa_{T}\right)$ and lattice thermal conductivity $\left(\kappa_{\mathrm{L}}\right)$ of several typical $\mathrm{CoSb}_{3}$-based solid solution alloy materials, and $Z T$ values of several typical $\mathrm{CoSb}_{3}$-based filled skutterudites TE materials

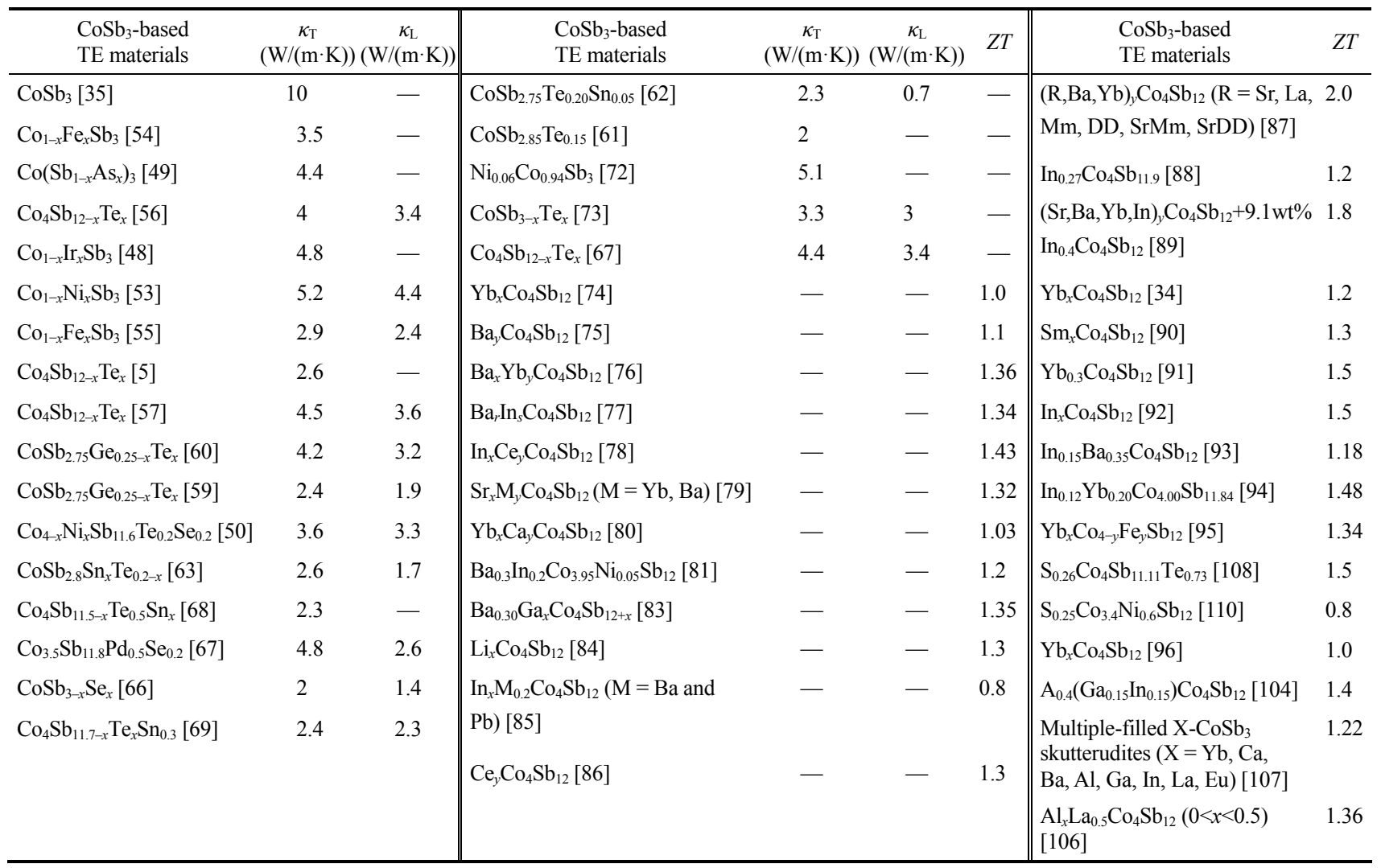


of chemical reactions involved has been developed by Toprak et al. [151] and Wang et al. [152]. High-density grain boundaries produced by nanocrystallization can strongly scatter electrons and phonons, leading to the decrease in the $\kappa$ of $\mathrm{CoSb}_{3}$ material. Compared to single crystal and annealed polycrystalline $\mathrm{CoSb}_{3}$ materials, the room-temperature $\kappa$ is significantly reduced by nearly one order of magnitude, reaches $1.5-2.2 \mathrm{~W} /(\mathrm{m} \cdot \mathrm{K})$. Yu et al. [126] used MA-SPS technology to prepare $\mathrm{CoSb}_{3}$ bulk TE materials with a minimum average particle size of $150 \mathrm{~nm}$. There is a little effect on $\kappa_{\mathrm{E}}$, whereas the $\kappa_{\mathrm{L}}$ is remarkable reduced when the grain size of the material is reduced from micrometer scale to nanometer scale. $\mathrm{CoSb}_{3}$ bulk materials with an average grain size of $150 \mathrm{~nm}$ were prepared by solvothermal method combined with SPS technique. The $Z T$ value of this $\mathrm{CoSb}_{3}$ nanocrystalline material reached 0.61 at $725 \mathrm{~K}$ because of the remarkable decrease in $\kappa$ and the increase in the $\alpha$ [133].

Rogl et al. [138] prepared a series of nanostructured $(\mathrm{Mm}, \mathrm{Sm})_{y} \mathrm{Co}_{4} \mathrm{Sb}_{12}$ materials by a technology that consists of rapid reaction melting, high energy ball milling, and hot pressing. A lower $\kappa$ was obtained because of a large number of nanostructures in the material (Figs. 7(a) and $7(\mathrm{c}))$. The maximum $Z T$ value reached 1.6 at 825 $\mathrm{K}$ under certain ball milling and hot pressing conditions
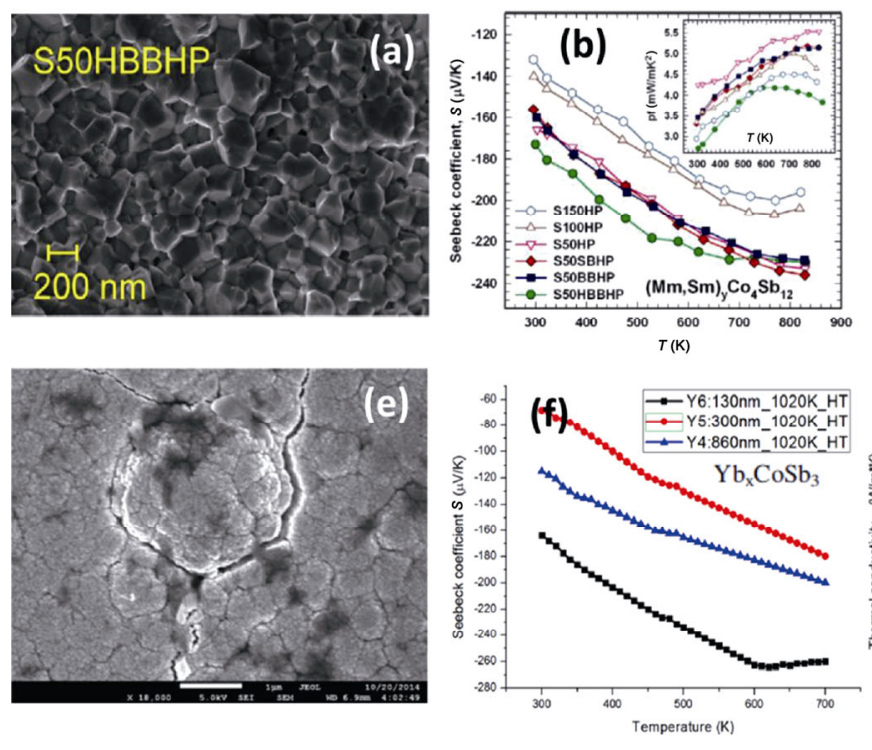

as shown in Fig. 7(d). Yb-filled $\mathrm{CoSb}_{3}$ skutterudite films were prepared by DC-reactive magnetron sputtering [142]. Higher electrical and thermal transport properties were presented after the heat treatment at $1020 \mathrm{~K}$ as shown in Figs. $7(\mathrm{e})-7(\mathrm{~g})$. The $Z T$ value reached 0.48 at $700 \mathrm{~K}$ for the film with a thickness of $130 \mathrm{~nm}$ (Fig. $7(\mathrm{~h})$ ). This $Z T$ value of the film is only between half and one third of the bulk materials because of the lower mobility. Recently, Ag-doped $\mathrm{CoSb}_{3}$ thin films were prepared by inter-layer diffusion method [145]. This film has a higher power factor value of $0.11 \mathrm{~mW} \cdot \mathrm{m}^{-1} \cdot \mathrm{K}^{-2}$ at $573 \mathrm{~K}$, which is 5 times that of undoped $\mathrm{CoSb}_{3}$ samples. In summary, the low-dimensionalization of the material structure is also an effective way to improve the TE transport properties of the $\mathrm{CoSb}_{3}$-based materials.

Introducing special structure. The results of theoretical and experimental studies showed that the phonon thermal conductivity can be significantly reduced without the deterioration of electrical transport properties by the introduction of special structures (such as micro-nanopores, nano-core shell structures, etc.) in bulk materials $[10,153,154]$. Therefore, these special structures may be introduced into the TE material to decrease significantly the $\kappa_{\mathrm{L}}$ and further improve its TE properties by enhancing the multi-scale phonons scattering. Porous (Ba,In) double-filled skutterudite materials with pore
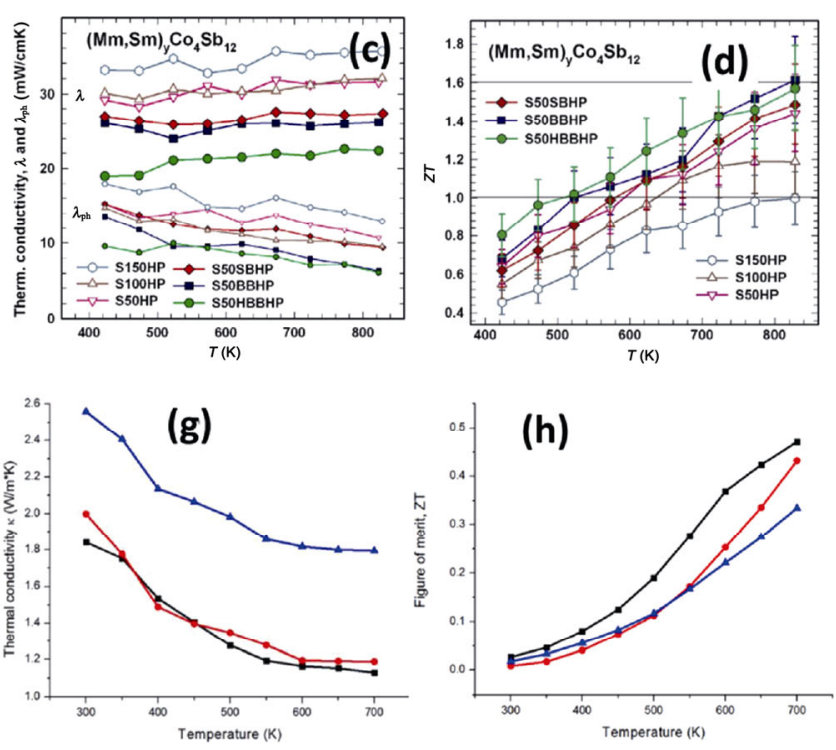

Fig. $7 \mathrm{CoSb}_{3}$-based TE materials with low dimensional nanostructure. (a) SEM image of the broken surface of $(\mathrm{Mm}, \mathrm{Sm})_{y} \mathrm{Co}_{4} \mathrm{Sb}_{12}$ (S50HBBHP sample); temperature dependence of (b) Seebeck coefficient, (c) thermal conductivity $\lambda$ and lattice thermal conductivity $\lambda_{\text {ph }}$, and (d) $Z T$ values of n-type $(\mathrm{Mm}, \mathrm{Sm})_{y} \mathrm{Co}_{4} \mathrm{Sb}_{12}$; the inset in (b) shows the temperature dependence of power factor. Reproduced with permission from Ref. [138], (C) Acta Materialia Inc. 2014. (e) SEM surface image of $\mathrm{Yb}_{x} \mathrm{Co}_{4} \mathrm{Sb}_{12}$ thin film (1020 K heat treatment Y4 sample); (f) Seebeck of $1020 \mathrm{~K}$ heat treated $\mathrm{Yb}_{x} \mathrm{Co}_{4} \mathrm{Sb}_{12}$ thin films with different thicknesses; $\left(\mathrm{g}\right.$ ) thermal conductivity of $\mathrm{Yb}_{x} \mathrm{Co}_{4} \mathrm{Sb}_{12}$ film at different thicknesses with temperature dependent; (h) figure of merit, $Z T$ values of $\mathrm{Yb}_{x} \mathrm{Co}_{4} \mathrm{Sb}_{12}$ films with different thicknesses. Reproduced with permission from Ref. [142], (C) AIP Publishing LLC. 2015. 
diameter about 1-4 $\mu \mathrm{m}$ containing a disordered arrangement of microporous structures have been prepared by the decomposition of metastable $\mathrm{ZnSb}$ inclusions induced by the $\mathrm{Zn}$ sublimation [155], as shown in Fig. 8. The electron filtering effect caused by the nanostructures on the surface of the pore structure increased the $\alpha$. The percolation effect of conducted network composed of filled skutterudites did not change the electrical conductivity. The $\kappa_{\mathrm{L}}$ was dramatically decreased because of the enhanced pore-edge boundary scattering of long-wavelength phonons. As a result, a maximum $Z T$ of 1.36 was obtained at $800 \mathrm{~K}$, increased by $22.5 \%$ as compared to that of the bulk material with the same chemical composition. Recently, Ni-induced nuclear-shell structures [156] and micro-nanoporous structures [157] were also introduced in $\mathrm{CoSb}_{3}$-based materials, as shown in Fig. 9. By using the strong scattering of these special structures on phonons, the $\kappa_{\mathrm{L}}$ of $\mathrm{CoSb}_{3}$-based materials was significantly reduced and the $Z T$ value was also remarkably improved. Therefore, the introduction of the special structure is also considered to be an effective method for improving the TE properties of $\mathrm{CoSb}_{3}$-based materials.

In addition, some special structures (such as in situ nanostructures [158], dislocation arrays [159,160], nanocrystalline polymer, and lattice distortion [161]) can also be introduced into the $\mathrm{CoSb}_{3}$-based materials by the microstructure and composition engineering [158,162], dislocation engineering [159] or grain boundary engineering [160], pressure regulation [161], and novel preparation methods [163-165]. The introduction of these special structures can also significantly improve the TE properties of $\mathrm{CoSb}_{3}$-based materials.

Nanocomposite. The introduction of the nanoscale second-phase is also an effective way to significantly improve TE properties of $\mathrm{CoSb}_{3}$-based materials at the nanometer- and mesoscopic-scale in addition to the low dimensionality and the introduction of special structure discussed above. The study found that the TE properties of the matrix material can also be significantly improved by introducing the nanoscale second-phase into the matrix to form nanocomposite TE materials [166]. Intragranular and grain boundary dispersion are generally the dispersion state of the nanoscale second-phase in the matrix material.
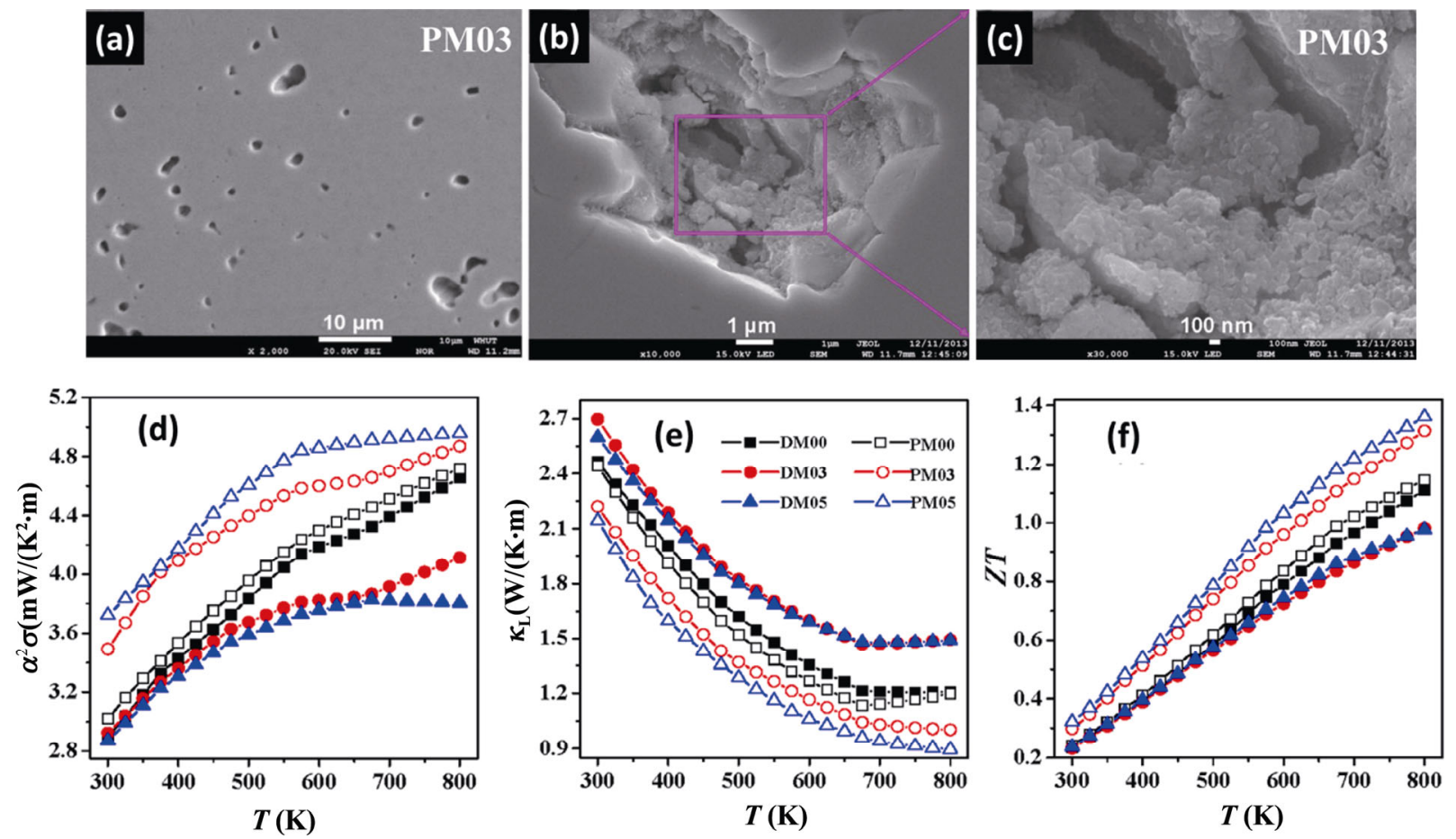

Fig. 8 Microstructure and thermoelectric properties of the dense (DM) and microporous $x \mathrm{Zn} / \mathrm{Ba}_{0.3} \mathrm{In}_{0.3} \mathrm{Co}_{4} \mathrm{Sb}_{12}$ materials (PM), $\mathrm{Zn}$ particles were added in the as-prepared $\mathrm{Ba}_{0.3} \mathrm{In}_{0.3} \mathrm{Co}_{4} \mathrm{Sb}_{12}$ powders before SPS sintering according to molar ratio of $\mathrm{Zn}: \mathrm{Ba}_{0.3} \mathrm{In}_{0.3} \mathrm{Co}_{4} \mathrm{Sb}_{12}=x: 1(x=0,0.3,0.5)$. The dense materials were named as DM00, DM03, and DM05, respectively. All the dense materials were annealed at $753 \mathrm{~K}$ for $72 \mathrm{~h}$ to obtain $\mathrm{Ba}_{0.3} \mathrm{In}_{0.3} \mathrm{Co}_{4} \mathrm{Sb}_{12}$ porous materials (PM). The resulting porous materials were termed as PM00, PM03, and PM05, respectively. (a) SEI photographs of PM03; (b, c) FESEM photographs of the porous structures of PM03. Temperature dependence of (d) power factor, (e) lattice thermal conductivity, and (f) $Z T$ values for the DM and PM materials. Reproduced with permission from Ref. [155], C AIP Publishing LLC. 2014. 
(a)

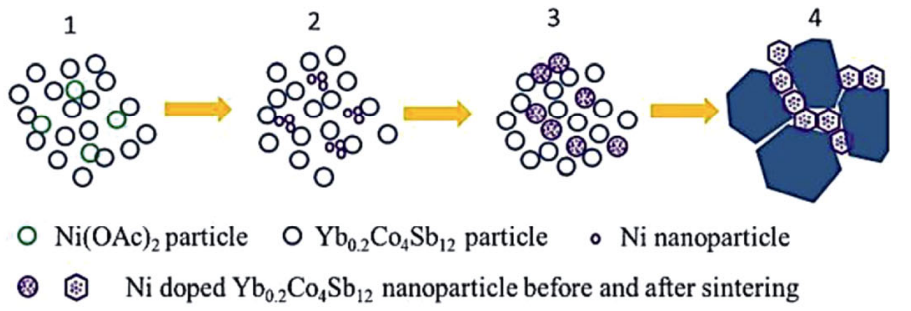

(c)

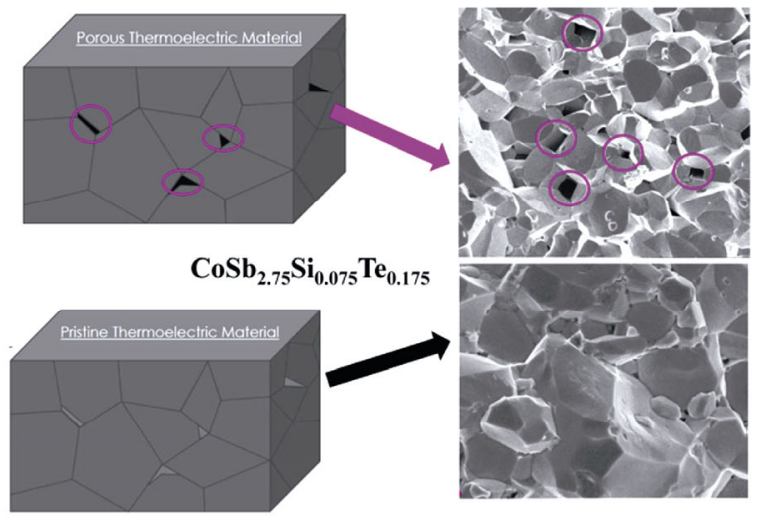

(d)
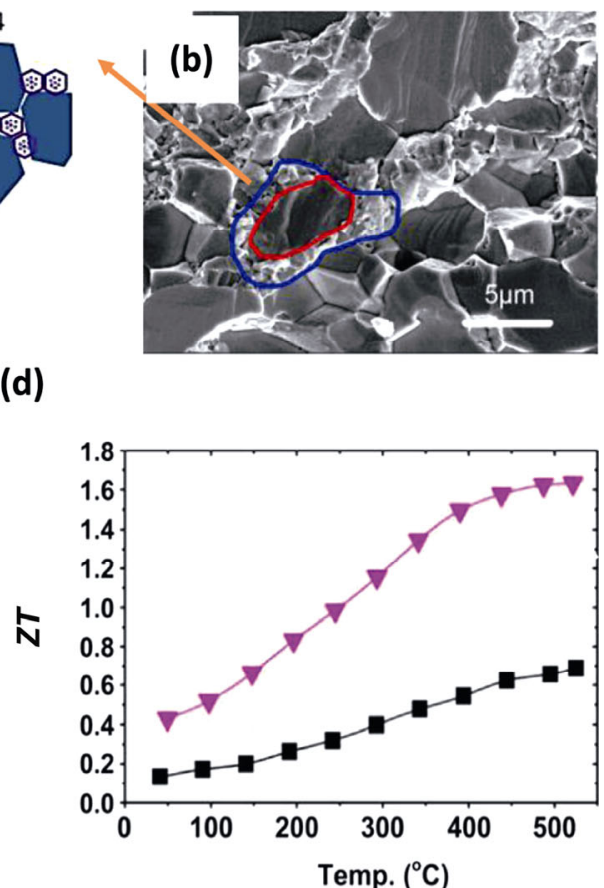

Fig. $9 \mathrm{CoSb}_{3}$-based materials with special structure. (a) A sketch map for the whole forming process of the "core-shell" structure in $\mathrm{Yb}_{0.2} \mathrm{Co}_{4} \mathrm{Sb}_{12}+x \mathrm{wt} \% \mathrm{Ni}$ samples. The large blue polygons represent the normal $\mathrm{Yb}_{0.2} \mathrm{Co}_{4} \mathrm{Sb}_{12}$ grains in the sintered bulk materials. (b) SEM fractograph of the $\mathrm{Yb}_{0.2} \mathrm{Co}_{4} \mathrm{Sb}_{12}+0.2 \mathrm{wt} \% \mathrm{Ni}$ samples. Reproduced with permission from Ref. [156], (C) The Royal Society of Chemistry 2015. (c) Schematic illustration and SEM fractographs of $\mathrm{CoSb}_{2.75} \mathrm{Si}_{0.075} \mathrm{Te}_{0.175}$ material with pristine and porous; (d) temperature dependence of $Z T$ values for $\mathrm{CoSb}_{2.75} \mathrm{Si}_{0.075} \mathrm{Te}_{0.175}$ material with pristine and porous. Reproduced with permission from Ref. [157], (C) The Author(s) 2016.

The nanoscale second-phase dispersed in the intragranular and grain boundaries of the matrix material is smaller than the mean free path of the phonon, which can effectively scatter phonons to reduce the $\kappa_{\mathrm{L}}$. The electron is not easy to be scattered because of the size of the nanoscale second-phase is much larger than the mean free path of the electron, which has little effect on the electrical properties. The preparation of $\mathrm{CoSb}_{3}$-based nanocomposites by in-situ generation [78,167-177] or mechanical addition of nanoinclusions [178-193] is a common method to introduce the second phase. $\mathrm{In}_{x} \mathrm{Ce}_{y} \mathrm{Co}_{4} \mathrm{Sb}_{12}$ nanocomposites containing in-situ formed $\mathrm{InSb}$ nanophases $(10-80 \mathrm{~nm})$ were prepared by melt quenching, annealing, and spark plasma sintering [78], as shown in Figs. 10(a) and 10(b). The strong scattering of phonons by InSb nano phase resulted in the significant decrease in the $\kappa_{\mathrm{L}}$. Combined with the filling effect of the In and $\mathrm{Ce}$ atoms, the $Z T$ value of $\mathrm{In}_{0.2} \mathrm{Ce}_{0.15} \mathrm{Co}_{4} \mathrm{Sb}_{12}$ nanocomposite reached 1.43 at $800 \mathrm{~K}$. Xiong et al. [169] prepared a $\mathrm{Yb}_{0.26} \mathrm{Co}_{4} \mathrm{Sb}_{12} / 0.2 \mathrm{GaSb}$ nanocomposite containing GaSb nanoinclusions $(5-20 \mathrm{~nm})$ by in-situ method (Fig. 10(c)). The metastable filling atom Ga reacts with an excess of $\mathrm{Sb}$ to form $\mathrm{GaSb}$ nanoinclusion during the sample cooling process. Nanoscale GaSb can not only significantly enhance the power factor by the energy filtering effect generated by the interface potential between the nanoscale $\mathrm{GaSb}$ and $\mathrm{Yb}_{0.26} \mathrm{Co}_{4} \mathrm{Sb}_{12}$ matrix, but also significantly reduce the thermal conductivity. The $\mathrm{Yb}_{0.26} \mathrm{Co}_{4} \mathrm{Sb}_{12} / 0.2 \mathrm{GaSb}$ nanocomposite sample had a highest $Z T$ value of 1.45 at $850 \mathrm{~K}$. $\mathrm{CoSb}_{3}$-based nanocomposites were also prepared by mechanically adding nanoinclusions (Ag [179], $\mathrm{AgSbTe}_{2}$ [183], $\mathrm{Bi}_{2} \mathrm{Te}_{3}$ [189], $\mathrm{MoS}_{2}$ [190], etc.) in the $\mathrm{CoSb}_{3}$-based material, as shown in Figs. 10(e)-10(h). The $\kappa_{\mathrm{L}}$ can be reduced significantly through the strong scattering of phonons by nano inclusions, even like metal $\mathrm{Ag}$ nanoinclusions [179], the electrical transport properties can be significantly improved, and thus the TE properties of $\mathrm{CoSb}_{3}$ materials can also be significantly improved.

Recently, we prepared a series of magnetic nanocomposites $\mathrm{BaFe}_{12} \mathrm{O}_{19} / \mathrm{Ba}_{0.3} \mathrm{In}_{0.3} \mathrm{Co}_{4} \mathrm{Sb}_{12}$ by introducing $\mathrm{BaFe}_{12} \mathrm{O}_{19}$ magnetic nanoparticles into the $(\mathrm{Ba}, \mathrm{In})$ double-filled $\mathrm{CoSb}_{3}$ matrix material [21]. $\mathrm{BaFe}_{12} \mathrm{O}_{19}$ magnetic nanoparticles $(\sim 20-150 \mathrm{~nm})$ are uniformly dispersed on the grain boundary and interface of $\mathrm{Ba}_{0.3} \mathrm{In}_{0.3} \mathrm{Co}_{4} \mathrm{Sb}_{12}$ matrix (Fig. 11(a)). Some $\mathrm{BaFe}_{12} \mathrm{O}_{19}$ magnetic nanoparticles with less than $10 \mathrm{~nm}$ in diameter were embedded into the matrix grains (Fig. 11(b)). The 

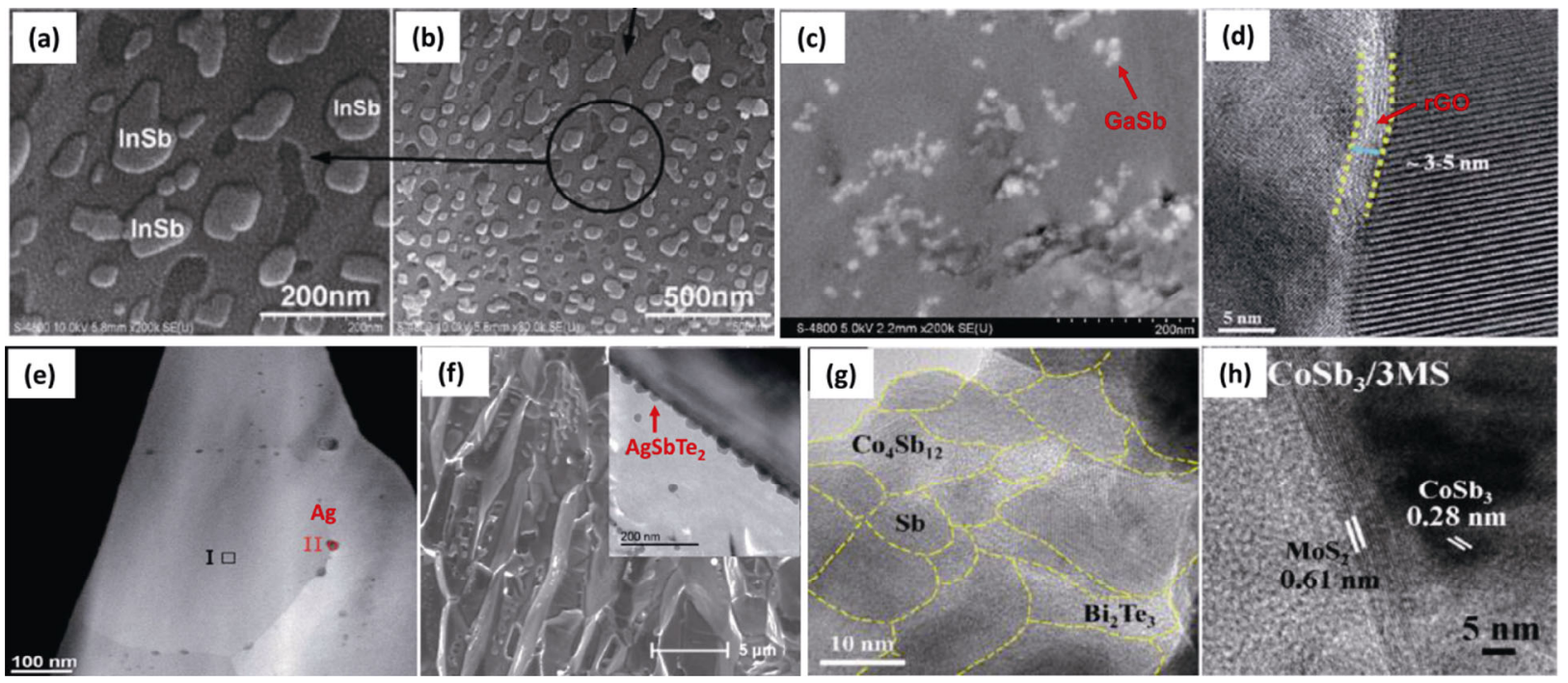

Fig. 10 Microstructure of $\mathrm{CoSb}_{3}$-based nanocomposite TE materials. (a, b) FESEM photographs of $\mathrm{In}_{x} \mathrm{Ce}_{y} \mathrm{Co}_{4} \mathrm{Sb}_{12}$ nanocomposite materials with in situ forming nanostructured InSb phase. Reproduced with permission from Ref. [78], (C) American Institute of Physics 2009. (c) FESEM photograph of $\mathrm{Yb}_{0.26} \mathrm{Co}_{4} \mathrm{Sb}_{12} / 0.2 \mathrm{GaSb}$ nanocomposite material. Reproduced with permission from Ref. [169], (c) Acta Materialia Inc. 2010. (d) HETEM photograph of $\mathrm{Yb}_{y} \mathrm{Co}_{4} \mathrm{Sb}_{12} / \mathrm{rGO}$ nanocomposite material. Reproduced with permission from Ref. [170], (C) The Royal Society of Chemistry 2015. (e) TEM photograph of $\mathrm{Ag} / \mathrm{Ba}_{0.3} \mathrm{Co}_{4} \mathrm{Sb}_{12}$ nanocomposite material. Reproduced with permission from Ref. [179], (C) The Royal Society of Chemistry 2012. (f) FESEM and TEM photographs of $\mathrm{AgSbTe} 2 \mathrm{Yb}_{0.2} \mathrm{Co}_{4} \mathrm{Sb}_{12}$ nanocomposite material. Reproduced with permission from Ref. [183], (C) The Royal Society of Chemistry 2015. (g) TEM photograph of $\mathrm{Bi}_{2} \mathrm{Te}_{3} / \mathrm{CoSb}_{3}$ nanocomposite material. Reproduced with permission from Ref. [189], (C) IOP Publishing Ltd. 2018. (h) TEM photograph of $\mathrm{MoS}_{2} / \mathrm{CoSb}_{3}$ nanocomposite material. Reproduced with permission from Ref. [190], (C) Elsevier B.V. 2017.
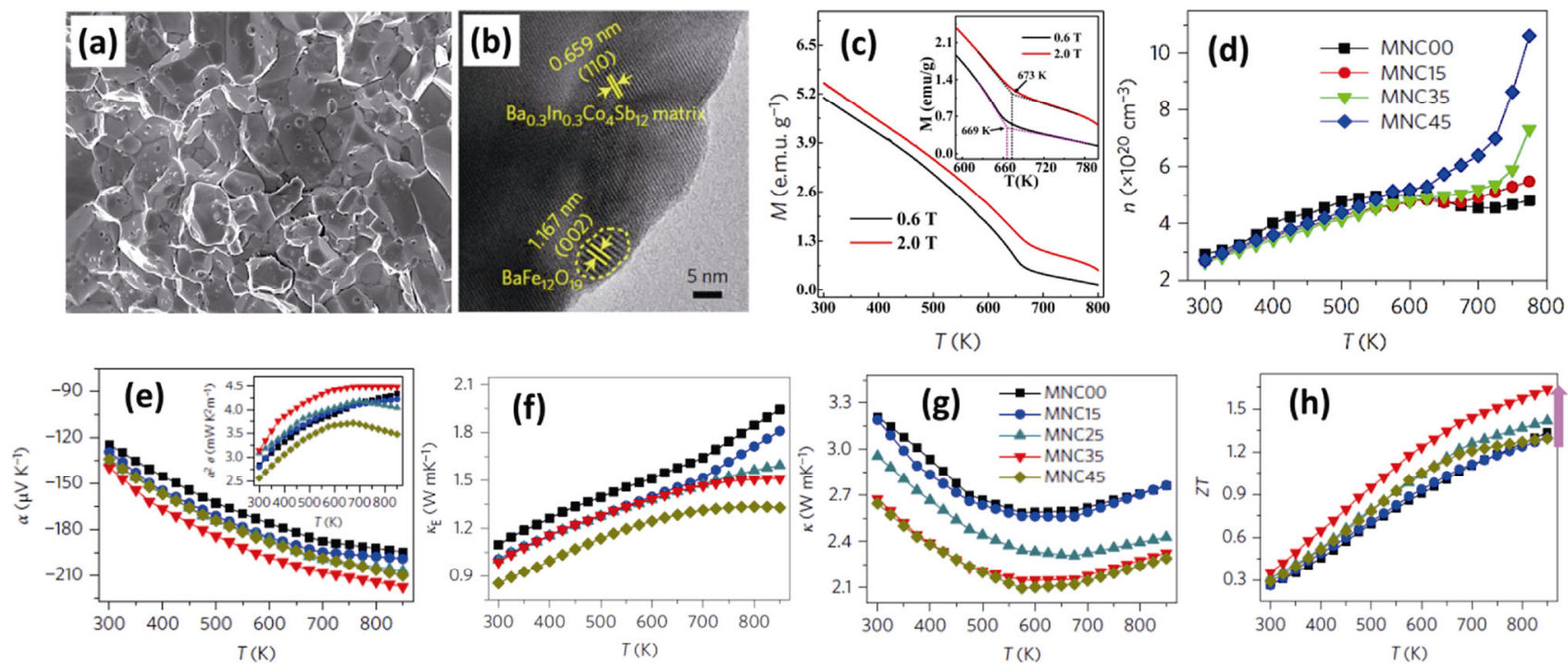

Fig. 11 Performance deterioration of $\mathrm{Ba}_{0.3} \mathrm{In}_{0.3} \mathrm{Co}_{4} \mathrm{Sb}_{12}$ matrix in the intrinsic excitation region can be suppressed through the magnetic transition of permanent magnet nanoparticles. (a) FESEM image of the $0.45 \% \mathrm{BaFe}_{12} \mathrm{O}_{19} / \mathrm{Ba}_{0.3} \mathrm{In}_{0.3} \mathrm{Co}_{4} \mathrm{Sb}_{12}(\mathrm{MNC})$ magnetic nanocomposite TE material; (b) HRTEM MNC45 sample; (c) Curie temperature of $\mathrm{BaFe}_{12} \mathrm{O}_{19}$ nanoparticles; temperature dependences of (d) carrier concentration $n$, (e) Seebeck coefficient, (f) electronic thermal conductivity $\kappa_{\mathrm{L}}$, (g) lattice thermal conductivity $\kappa_{\mathrm{L}}$, and (h) $Z T$ figure of merit of $x \mathrm{BaFe}_{12} \mathrm{O}_{19} / \mathrm{Ba}_{0.3} \mathrm{In}_{0.3} \mathrm{Co}_{4} \mathrm{Sb}_{12}$. The inset in (e) shows the temperature dependences of power factor $\left(\alpha^{2} \sigma\right)$ for $x \mathrm{BaFe}_{12} \mathrm{O}_{19} / \mathrm{Ba}_{0.3} \mathrm{In}_{0.3} \mathrm{Co}_{4} \mathrm{Sb}_{12}$. Reproduced with permission from Ref. [21], (C) Macmillan Publishers Limited, part of Springer Nature 2016.

magnetic phase transition temperatures of these $\mathrm{BaFe}_{12} \mathrm{O}_{19}$ magnetic nanoparticles from ferromagnetic to paramagnetic are about 669-673 K (Fig. 11(c)), which is very close to the intrinsic excitation temperature 
$(675 \mathrm{~K})$ of the matrix. $\mathrm{BaFe}_{12} \mathrm{O}_{19}$ nanoparticles with ferromagnetic state below $675 \mathrm{~K}$ can capture electrons by the spherical micromagnetic field induced by the electron spin of $\mathrm{Fe}^{3+}$ [194]. $\mathrm{BaFe}_{12} \mathrm{O}_{19}$ nanoparticles with paramagnetic state above $675 \mathrm{~K}$ released the captured electrons because of disappearance of the micromagnetic field, leading to a significant increase in electron concentration (Fig. 11(d)). $\mathrm{BaFe}_{12} \mathrm{O}_{19}$ magnetic nanoparticles played an "electronic repository" role. Insulating $\mathrm{BaFe}_{12} \mathrm{O}_{19}$ magnetic nanoparticles caused the decrease in the $\sigma$ and the increase in the $\alpha$ of the composites. The $\alpha$ of the composites significantly improved (Fig. 11(e)) combined with the magnon-drag effect caused by $\mathrm{BaFe}_{12} \mathrm{O}_{19}$ magnetic nanoparticles. The magnetic phase transition produced by $\mathrm{BaFe}_{12} \mathrm{O}_{19}$ magnetic nanoparticles from ferromagnetic to paramagnetic significantly affected the TE transport properties of the matrix, especially the high-temperature electron thermal conductivity, as shown in Fig. 11(f). The high-temperature $Z T$ value of the composites is greatly improved because of the significant decrease of high-temperature thermal conductivity. The maximum $Z T$ value reached 1.6 at
$850 \mathrm{~K}$, increased by $22 \%$ compared with that of the matrix (Fig. 11(h)). Very recently, we also prepared a series of magnetic nanocomposites $\mathrm{BaFe}_{12} \mathrm{O}_{19} / \mathrm{In}_{0.25} \mathrm{Co}_{4} \mathrm{Sb}_{12}$ by introducing $\mathrm{BaFe}_{12} \mathrm{O}_{19}$ nanometer suspension into the In-filled $\mathrm{CoSb}_{3}$ matrix material [195]. $\mathrm{BaFe}_{12} \mathrm{O}_{19}$ nanometer suspension can not only solve the agglomeration phenomenon of nanoparticles in nanocomposites (Figs. 12(a) and 12(b)), but also suppress the deterioration of high-temperature thermoelectric properties of In-filled skutterudite by suppressing the decrease of hightemperature Seebeck coefficient (Figs. 12(c) and 12(d)). The decrease of high-temperature Seebeck coefficient was significantly suppressed by the magnetic phase transition of $\mathrm{BaFe}_{12} \mathrm{O}_{19}$ magnetic nanoparticles from ferromagnetism to paramagnetism. These results further confirmed that the magnetic phase transition of $\mathrm{BaFe}_{12} \mathrm{O}_{19}$ magnetic nanoparticles can significantly suppress the deterioration of high-temperature thermoelectric properties of filled skutterudite materials.

In addition, we also prepared $\mathrm{Co} / \mathrm{Ba}_{0.3} \mathrm{In}_{0.3} \mathrm{Co}_{4} \mathrm{Sb}_{12}$ magnetic nanocomposites by introducing the soft magnetic Co nanoparticles (or $\mathrm{Fe}$, Ni nanoparticles) in (Ba,In)

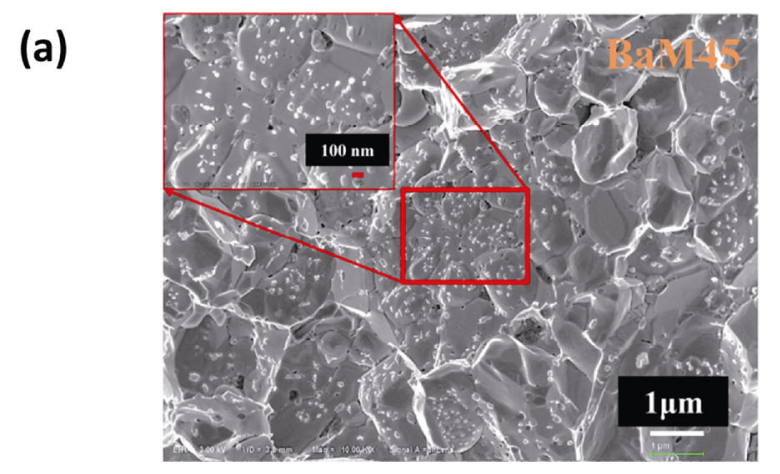

(b)
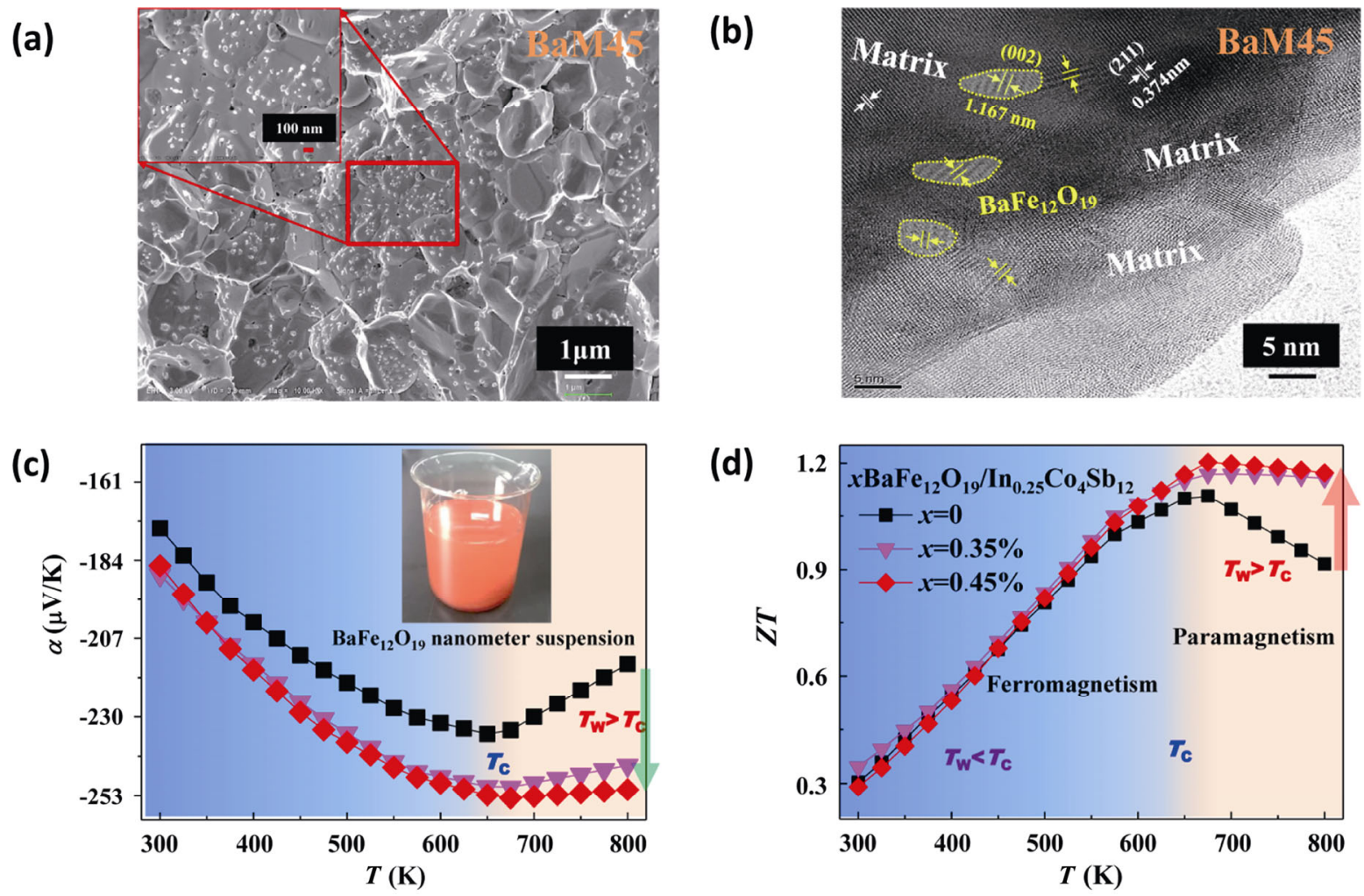

Fig. 12 (a) FESEM image of $0.45 \% \mathrm{BaFe}_{12} \mathrm{O}_{19} / \mathrm{In}_{0.25} \mathrm{Co}_{4} \mathrm{Sb}_{12}$ (BaM45) bulk material produced by an ultrasonic mixing of $\mathrm{BaFe}_{12} \mathrm{O}_{19}$ nanometer suspension and $\mathrm{In}_{0.25} \mathrm{Co}_{4} \mathrm{Sb}_{12}$ matrix material combined with spark plasma sintering; (b) HRTEM image of BaM45 bulk material; temperature dependences of (c) Seebeck coefficient and (d) $Z T$ values of $\operatorname{In}_{0.25} \mathrm{Co}_{4} \mathrm{Sb}_{12}$ matrix and $\mathrm{BaFe}_{12} \mathrm{O}_{19} / \mathrm{In}_{0.25} \mathrm{Co}_{4} \mathrm{Sb}_{12}$ nanocomposites; $T_{\mathrm{W}}$ is the work temperature, $T_{\mathrm{C}}$ is the Curie temperature. Reproduced with permission from Ref. [195], (C) American Chemical Society 2019. 
double-filled $\mathrm{CoSb}_{3}$ materials [22]. Co nanoparticles were uniformly dispersed on the grain boundaries and interfaces of the $\mathrm{Ba}_{0.3} \mathrm{In}_{0.3} \mathrm{Co}_{4} \mathrm{Sb}_{12}$ matrix, as shown in Figs. 13(a) and 13(b). Even some Co nanoparticles with $5-10 \mathrm{~nm}$ in diameter were embedded into the grains of the matrix (Fig. 13(c)). These uniformly dispersed nanoparticles on the grain boundaries and surface of the matrix significantly enhanced phonon scattering and caused the significant decrease in the $\kappa_{\mathrm{L}}$ of the composite material, which leads to a significant decrease in the total thermal conductivity, as shown in Fig. 13(d). The superparamagnetic transition temperature of Co nanoparticles with 5-10 nm in diameter (Fig. 13(e)) was approximately $442 \mathrm{~K}$ (Fig. 13(f)), which was basically consistent with the $M-H$ experimental test result of $450 \mathrm{~K}$ (Fig. 13(g)). The random turning of magnetic domains in Co nanoparticles with superparamagnetic state can cause multiple scattering of electrons (Fig. 13(h)), which enhanced the scattering factor $r$ of the composites, resulting in the increase of the $\alpha$, as shown in Fig. 13(k). In addition, based on the metal and semiconductor contact theory [196], the difference of work function between the Co nanoparticles and the matrix caused a charge transfer (Fig. 13(i)). The charge transfer of the $4 \mathrm{~s}$ electrons from the Co nanoparticles to the matrix caused the increase in the $\sigma$ of the composites (Fig. 13(j)). Charge transfers of superparamagnetic Co nanoparticles can remarkably improve the electrical transport properties of composites. At the same time, the multiple scattering of electrons caused by random turning of magnetic domains can significantly increase the $\alpha$ and enhance phonon scattering. The $Z T$ value of
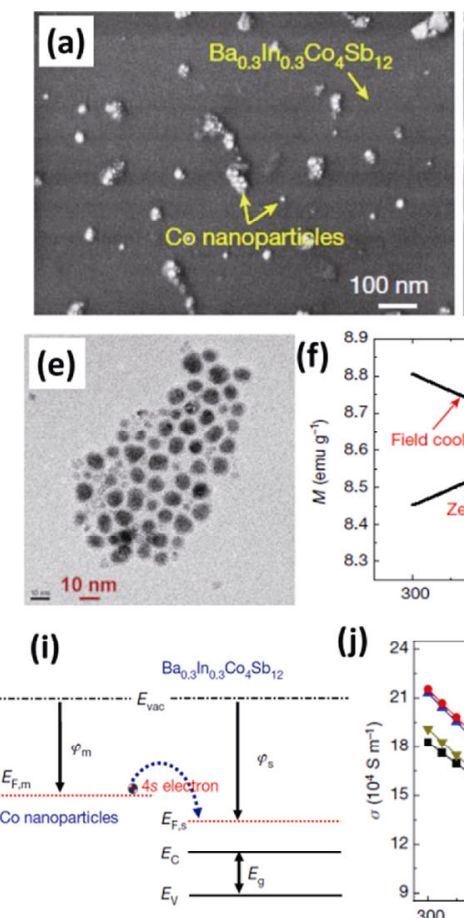

(j)
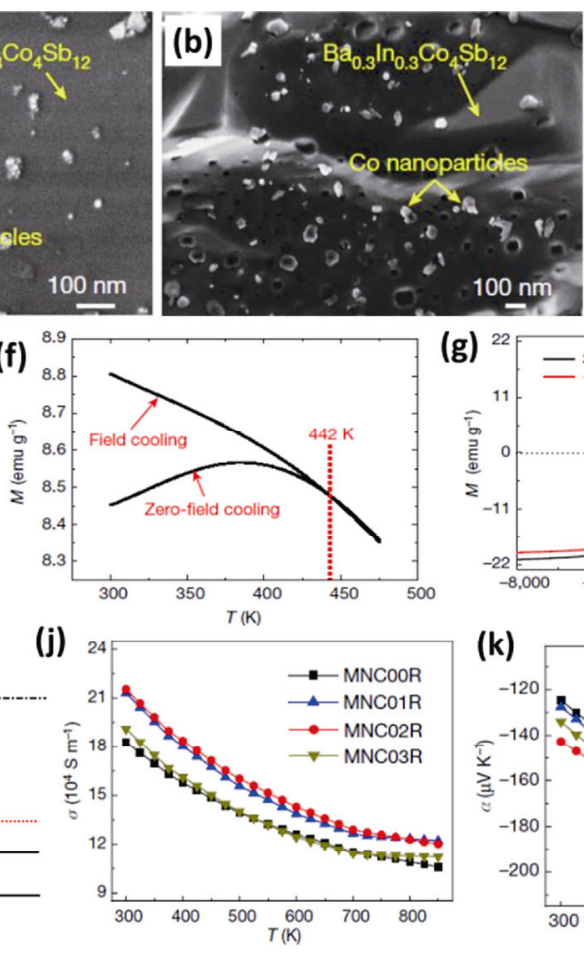
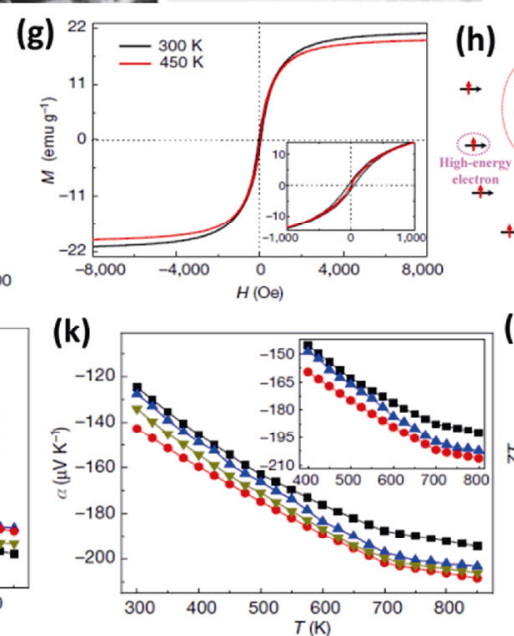

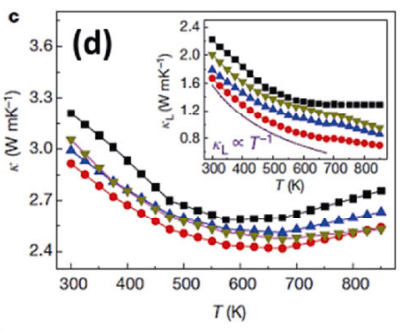

(h)
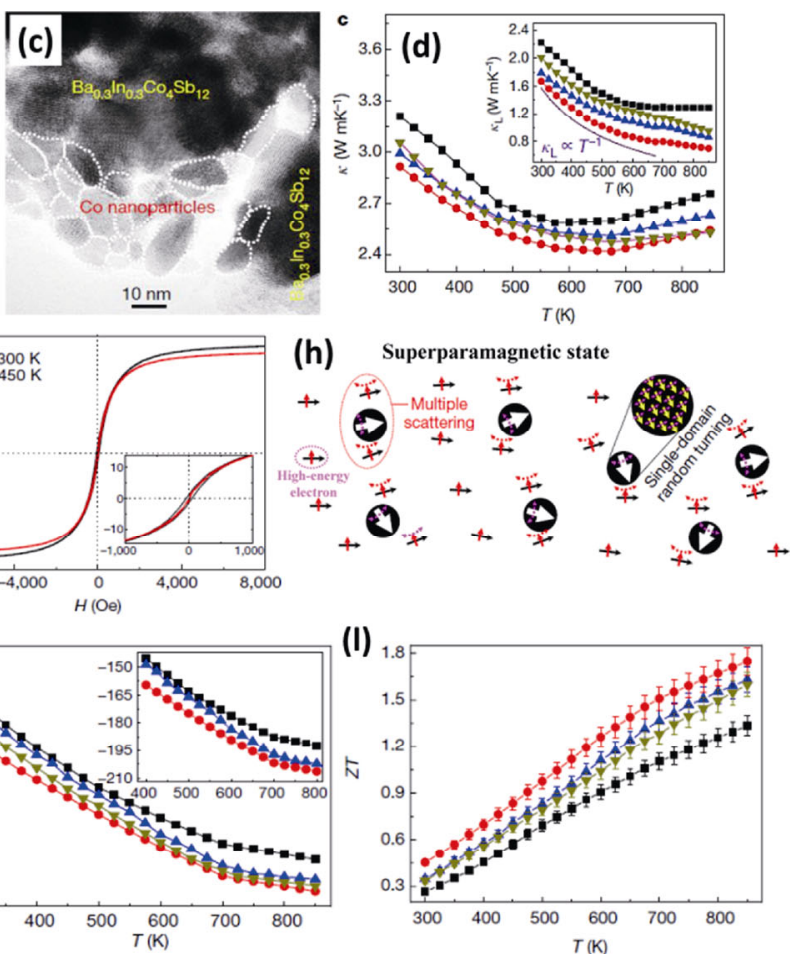

Fig. 13 Superparamagnetic enhancement of TE performance in $x \mathrm{Co} / \mathrm{Ba}_{0.3} \mathrm{In}_{0.3} \mathrm{Co}_{4} \mathrm{Sb}_{12}$ magnetic nanocomposite TE materials. $(\mathrm{a}-\mathrm{c})$ Microstructures of the as-prepared powders and bulk materials of $x \mathrm{Co} / \mathrm{Ba}_{0.3} \mathrm{In}_{0.3} \mathrm{Co}_{4} \mathrm{Sb}_{12}$ with $x=0.2 \%$ (MNC02R); (d) temperature dependences of thermal conductivity $\kappa$ for $x \mathrm{Co} / \mathrm{Ba}_{0.3} \mathrm{In}_{0.3} \mathrm{Co}_{4} \mathrm{Sb}_{12}$; the inset in (d) shows the temperature dependence of lattice thermal conductivity $\kappa_{\mathrm{L}}$; (e) TEM image of the Co nanoparticles (diameters of 5-10 nm); (f) ZFC and FC $M-T$ curves of Co nanoparticles; (g) $M-H$ curves at 300 and $450 \mathrm{~K}$ of Co nanoparticles; (h) multiple scattering of electrons (indicated by the small red dashed arrows) as a result of the random turning of magnetic domains (indicated by the small purple dashed arrows) within the superparamagnetic Co nanoparticles; (i) schematic of the charge transfer of $4 \mathrm{~s}$ electrons from the Co nanoparticles to the matrix; $E_{\mathrm{vac}}$ is the vacuum energy, $E_{\mathrm{F}, \mathrm{m}}$ and $E_{\mathrm{F}, \mathrm{s}}$ are the Fermi levels of the Co nanoparticles and the matrix, respectively, $E_{\mathrm{C}}$ is the energy of the conduction band minimum, $E_{\mathrm{V}}$ is the energy of the valence band maximum, and $E_{\mathrm{g}}$ is the bandgap; $\varphi_{\mathrm{m}}$ and $\varphi_{\mathrm{s}}$ are the work functions of the Co nanoparticles and the matrix, respectively; temperature dependences of (j) electric conductivity $\sigma$, (k) Seebeck coefficient $\alpha$, and (l) figure of merit $Z T$ for $x \mathrm{Co} / \mathrm{Ba}_{0.3} \mathrm{In}_{0.3} \mathrm{Co}_{4} \mathrm{Sb}_{12}$; the inset in (k) highlights the abnormal temperature dependence of the Seebeck coefficient for MNC01R (blue). Reproduced with permission from Ref. [22], (C) Macmillan Publishers Limited, part of Springer Nature 2017. 
the composites was significantly improved combining with the strong scattering of phonons by Co nanoparticles at the grain boundaries and surface of the matrix. The maximum $Z T$ value reached 1.8 at $850 \mathrm{~K}$, increased by $32 \%$ compared with that of the matrix. The magnetic composites composed of $\mathrm{Fe}$ or $\mathrm{Ni}$ nanoparticles and $\mathrm{Ba}_{0.3} \mathrm{In}_{0.3} \mathrm{Co}_{4} \mathrm{Sb}_{12}$ matrix were also studied. It was found that the TE properties of the composites can be also significantly improved by the superparamagnetic Fe or Ni nanoparticles.

In addition, introducing nanoscale second-phase into $\mathrm{CoSb}_{3}$-based materials to form nanocomposites can not only significantly reduce the thermal conductivity, but also may significantly affect the mechanical properties [158,177,197-201] of $\mathrm{CoSb}_{3}$-based materials. Rogl and Rogl [199] reviewed systematically that nanoparticles can obviously change the mechanical properties of skutterudite TE materials. They claimed that as long as the nanoscale second-phases do not increase the porosity of the samples, the smaller and more nanoscale secondphases can significantly enhance the mechanical properties of the nanocomposites. This is mainly due to the establishment of a resistance against crack growth, a pinning effect in the embedded skutterudite matrix and a stronger interface between skutterudite matrix and nanoscale second-phases. The mechanical properties of different kinds of $\mathrm{CoSb}_{3}$-based nanocomposites were obviously changed by introducing some nanoparticles like $\mathrm{Yb}_{2} \mathrm{O}_{3}$ [158], TiN [181,200], CoAl [197], CoSi [179], and $\mathrm{SiC}$ [198]. Qin et al. [177] prepared $\mathrm{Yb}_{0.3} \mathrm{Co}_{4} \mathrm{Sb}_{12}$ with in situ formed CoSi nanoprecipitates by adding the extra $\mathrm{Co}$ and Si. Microstructure with multiscale CoSi nanoparticles shows that mechanical properties (hardness and indentation fracture toughness) were significantly improved owing to particle hardening, making it more competitive for practical applications.

\section{Non-equilibrium preparation}

Preparation of $\mathrm{CoSb}_{3}$-based TE materials by conventional melt, anneal, SPS process needs a long period (about 10 days). It is not conducive to large-scale production and impedes the final commercial use of $\mathrm{CoSb}_{3}$-based TE materials for power generation. Therefore, some non-equilibrium preparation methods, such as melt spinning combined with spark plasma sintering (MS-SPS) [202-204], self-propagating high-temperature synthesis (SHS) method [205-209], and high pressure synthesis
[66-70,210,211], have been adopted in recent years. Using these non-equilibrium preparation methods, the preparation period of the material was greatly shortened. Materials prepared by non-equilibrium have the following advantages: (i) higher density; (ii) refined grain (nanostructure) and uniform element distribution; (iii) competitive transport properties compared with the materials prepared by traditional methods, and even higher than their properties.

\section{1 MS-SPS}

An improved MS-SPS preparation method based on the traditional preparation method has emerged in order to prepare $\mathrm{CoSb}_{3}$-based TE materials more quickly and cheaply. This method directly melts and spins the original raw materials. The entire process time was highly shortened from about 8 days for conventional method to less than about $40 \mathrm{~h}$. The microstructure and low-temperature TE transport properties of the materials prepared by MS-SPS method were systematically studied. The results showed the grain of the sample was arranged more closely. No obvious pores were observed between the large grains with smooth surface and the flocculent small grainy areas. Compared with the samples prepared by traditional methods, the grain of the MS-SPS sample was significantly refined, and the element distribution was also more homogeneous. Li et al. [202,203] prepared nanostructured $\mathrm{Yb}_{0.3} \mathrm{Co}_{4} \mathrm{Sb}_{12+y}$ and $\operatorname{In}_{x} \mathrm{Ce}_{y} \mathrm{Co}_{4} \mathrm{Sb}_{12+z}$ skutterudite TE materials by MS-SPS method, as shown in Fig. 14. The preparation cycle was significantly reduced from about 10 days of the traditional method to less than about $40 \mathrm{~h}$. Under this rapid preparation process, the grains of the bulk material after sintering were greatly refined, and a large number of nanoparticles $\left(\mathrm{Yb}_{2} \mathrm{O}_{3}\right.$ and $\left.\mathrm{InSb}\right)$ were also found on the matrix grains. A wide range of phonon was strongly scattered by these multi-scale grains. The $\kappa_{\mathrm{L}}$ was remarkably decreased and $Z T$ value was significantly enhanced compared with that of the materials prepared by traditional methods. $Z T$ value of the $\mathrm{In}_{0.2} \mathrm{Ce}_{0.15} \mathrm{Co}_{4} \mathrm{Sb}_{12}$ sample reached about 1.5 at $850 \mathrm{~K}$.

\section{2 SHS}

Self-propagating high-temperature synthesis (SHS) rapid preparation technology has been proposed by the Soviet Union for more than 50 years since the 1960s. It has been developed in the 1970s-1990s and widely used in the preparation of high temperature refractories [205], 

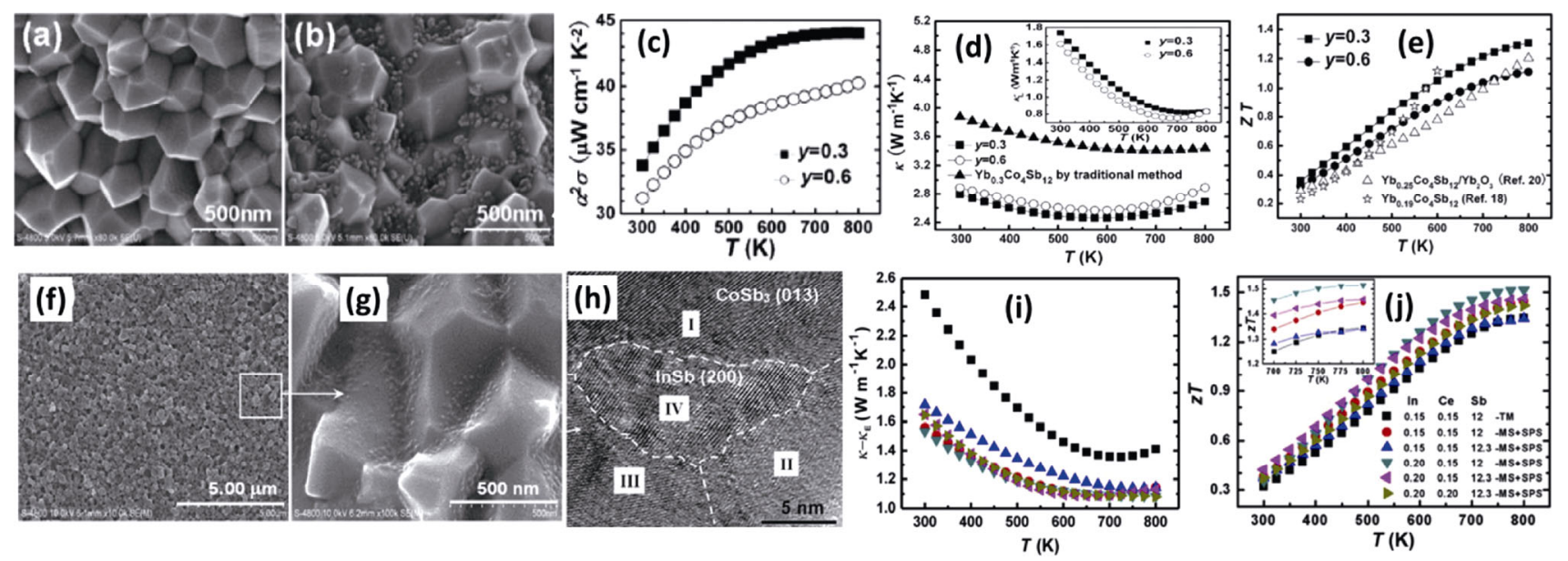

Fig. 14 Nanostructured $\mathrm{Yb}_{0.3} \mathrm{Co}_{4} \mathrm{Sb}_{12+y}$ and $\mathrm{In}_{x} \mathrm{Ce}_{y} \mathrm{Co}_{4} \mathrm{Sb}_{12+z}$ skutterudite TE materials prepared by the MS-SPS. FESEM photographs of bulk nanostructured $\mathrm{Yb}_{0.3} \mathrm{Co}_{4} \mathrm{Sb}_{12+y}$ after SPS: (a) $y=0.3$, (b) $y=0.6$. Temperature dependences of (c) power factor, (d) thermal conductivity, and (e) $Z T$ values for $\mathrm{Yb}_{0.3} \mathrm{Co}_{4} \mathrm{Sb}_{12+y}$ materials. Reproduced with permission from Ref. [202], (C) American Institute of Physics 2008. (f, g) FESEM and (h) HRTEM photographs of $\operatorname{In}_{0.15} \mathrm{Ce}_{0.15} \mathrm{Co}_{4} \mathrm{Sb}_{12}$ sample prepared by MS-SPS; temperature dependences of (i) lattice thermal conductivity and (j) $Z T$ values for $\operatorname{In}_{x} \mathrm{Ce}_{y} \mathrm{Co}_{4} \mathrm{Sb}_{12+z}$ skutterudite TE materials. Reproduced with permission from Ref. [203], (C) The Chinese Ceramic Society 2017.

high purity ceramic materials [206], and intermetallic compounds [207]. Spontaneous combustion wave is the basic feature of the reaction, which depends on exothermic reaction. The combustion synthesis reaction is very fast, usually in the time range of seconds. The synthesis is initiated by heating part of the sample locally, and once the heating ignition starts, the combustion wave will quickly pass through the remaining sample because the melting heat released in one zone is enough to maintain the reaction in the adjacent zone. The propagation of the combustion wave is fast, usually in a matter of seconds, and the final product usually has a higher purity. In other words, the heat released during SHS not only maintains the reaction but propagates it through the whole sample. For more than 40 years, SHS technology has not been used for synthesis of TE materials. Su et al. [208] applied SHS technology for the first time to rapidly prepare high-performance TE materials, which breaks the view that TE material cannot be synthesized by SHS based on traditional thermodynamic criteria. They also proposed a new criterion of thermodynamic universality for SHS reaction. Te-doped $\mathrm{CoSb}_{3}$ materials were first synthesized by SHS-PAS (plasma activated sintering) technology [209] as shown in Fig. 15. Te-doped $\mathrm{CoSb}_{3}$ based TE material prepared by this method has the following advantages: (i) the preparation time is greatly shortened from a few days of the conventional process to less than 20 min (Fig. 15(a)); (ii) this rapid preparation method allows a large amount of nanostructures to be retained in the material (Figs. 15(b)-15(d)), which is helpful to improve the thermal transport performance (Fig. 15(g)); (iii) compared with samples prepared by traditional processes, the samples prepared by SHS-PAS technology have good density and good electrical properties (Figs. 15(e)-15(f)). Therefore, the TE performance can also be significantly improved. The $Z T$ value of $\mathrm{CoSb}_{2.85} \mathrm{Te}_{0.15}$ sample prepared by SHS-PAS technology reached 0.98 at $820 \mathrm{~K}$ (Fig. 15(h)).

\section{Synergistic optimization}

To obtain high $Z T$ value, the TE material is required to have a high Seebeck coefficient and electrical conductivity, while having a low thermal conductivity. However these parameters are strongly interdependent and maximizing one transport parameter inevitably leads to diminishing the others. Therefore, it is very difficult to realize the decoupling of electrical performance and thermal conductivity. In recent years, some important progresses [212-215] have been made in the research of synergistic optimization of electrical and thermal transport properties for TE materials. These methods of synergistic optimization include structural phase transition [216], disordered structure [11,217], all-scale hierarchical architectures [26], band convergence [14], and so on. For $\mathrm{CoSb}_{3}$-based TE materials, there are many ways to achieve the synergistic optimization of their electrical and thermal transport properties, such as doping to form solid solution alloy [36,61,218], introducing filler atoms 
(a)
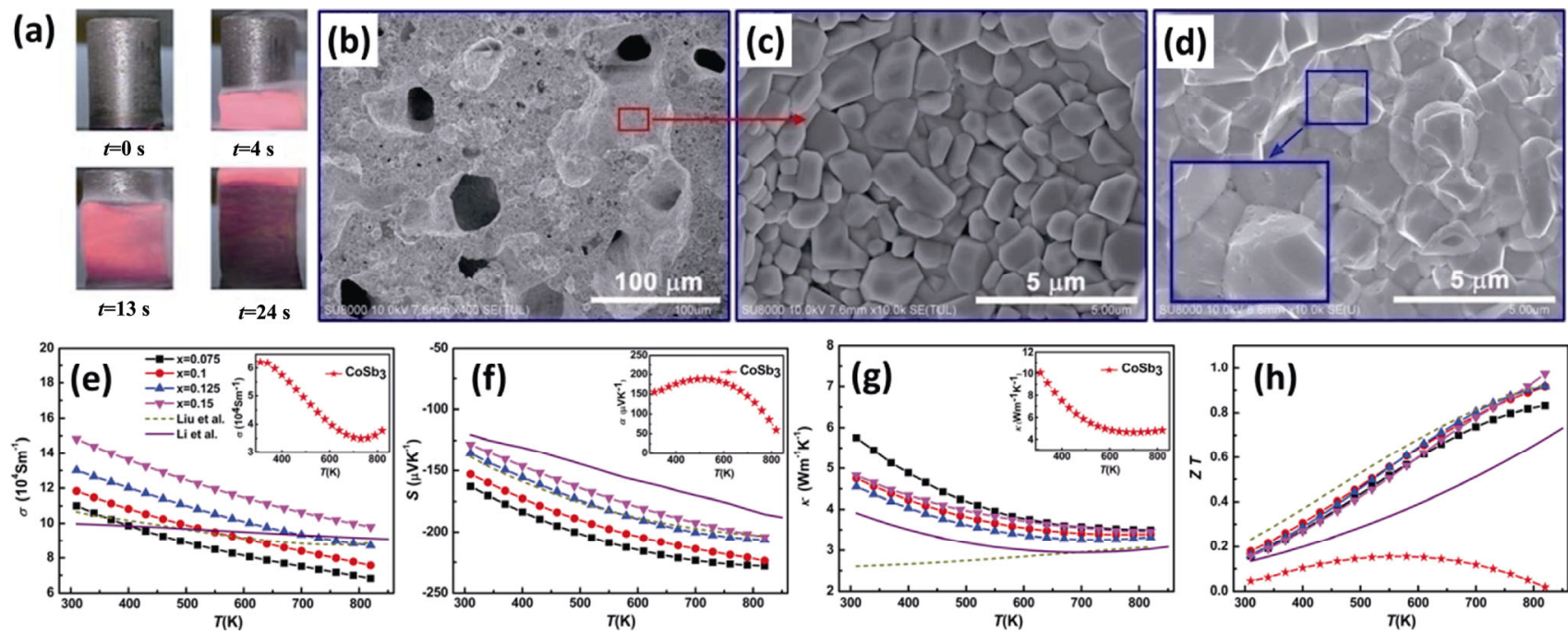

Fig. 15 Te-doped $\mathrm{CoSb}_{3}$ materials prepared by the SHS-PAS technique. (a) Different stages of the SHS process; (b, c) FESEM images of bulk $\mathrm{CoSb}_{3-x} \mathrm{Te}_{x}$ compounds after the SHS process; (d) FESEM image of the bulk $\mathrm{CoSb}_{3-x} \mathrm{Te}_{x}$ compound after SHS-PAS processing; temperature dependence of (e) electrical conductivity, (f) Seebeck coefficient, (g) thermal conductivity, and (h) the dimensionless figure of merit $Z T$ of $\mathrm{CoSb}_{3-x} \mathrm{Te}_{x}$ compounds prepared by the SHS-PAS technique. Insets in (e), (f), and (g) show TE properties of pure $\mathrm{CoSb}_{3}$ skutterudite. Reproduced with permission from Ref. [209], (C) The Royal Society of Chemistry 2014.

$[7,108,219]$, nanocomposites [21,22,172], and other means mentioned in the previous section.

The solid solution alloy formed by doping is realized by atom substitution at $\mathrm{Co}$ or $\mathrm{Sb}$ sites. Atomic substitution can not only reduce the phonons thermal conductivity by point defects induced by the fluctuations of mass and strain fields because of the difference of the mass and radius between the foreign atom and the guest atom, but also improve the electrical transport performance by the adjustment of the carrier concentration, so as to realize the synergistic optimization of electrical and thermal transport properties. The filled $\mathrm{CoSb}_{3}$ materials are formed by introducing the other atoms into the $\mathrm{Sb}_{12}$ icosahedral void of $\mathrm{CoSb}_{3}$. The introduction of foreign atoms can not only reduce the lattice thermal conductivity by the rattling of filled atoms in the $\mathrm{CoSb}_{3}$ void, but also improve the electrical transport performance by the adjustment of the carrier concentration. This is because the filled atoms can serve as the donor atom. Filled atom has different electronegativity from the framework atom $\mathrm{Sb}$, which is more electronegative than the donor atom. Therefore, the synergistic optimization of electrical and thermal transport properties can also be achieved by introducing the filled atoms. Zhao et al. [219] found that the electrical and thermal transport properties of n-type In-filled skutterudite TE materials $\mathrm{In}_{y} \mathrm{Co}_{4} \mathrm{Sb}_{12}$ can be optimized synergistically by three types of coexisting multi-localization transport behaviours in an independent way due to the introduction of foreign In atom, as shown in Figs. 16(d)-16(f). These are heatcarrying phonon-localized resonant scattering (Fig. 16(a)), accelerated electron movement (Fig. 16(b)) and increased density of states near the Fermi level (Fig. 16(c)).

In addition, introducing magnetic nanoscale secondphase into $\mathrm{CoSb}_{3}$-based materials to form magnetic nanocomposites can also achieve the synergistic optimization of electrical and thermal transport properties. As we mentioned in the previous discussion, magnetic nanocomposites were prepared by introducing hard magnetic nanoparticles $\left(\mathrm{BaFe}_{12} \mathrm{O}_{19}\right.$ nanoparticles) and soft magnetic nanoparticles (Co, Fe, or Ni nanoparticles) into the filled $\mathrm{CoSb}_{3}$ material $[21,22]$. The electrical and thermal transport properties of the composite materials were simultaneously improved by the magnetic phase transition of these introduced magnetic nanoparticles, strong phonons scattering by nanoparticles, and charge transfer between magnetic metal nanoparticles and $\mathrm{CoSb}_{3}$-based materials matrix. The decoupling of electrical properties and thermal conductivity was achieved, and the $Z T$ value of the composite materials was greatly enhanced.

\section{$5 \mathrm{CoSb}_{3}$-based TE devices}

TE energy conversion devices have attracted wide 
(a)

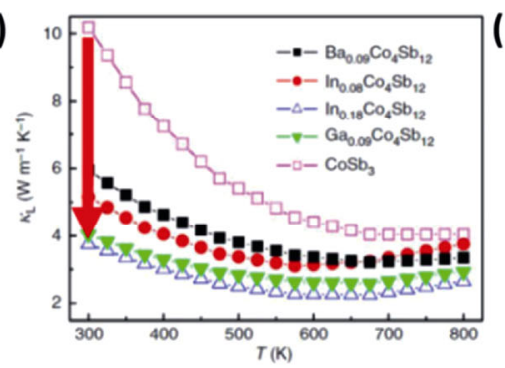

(d)

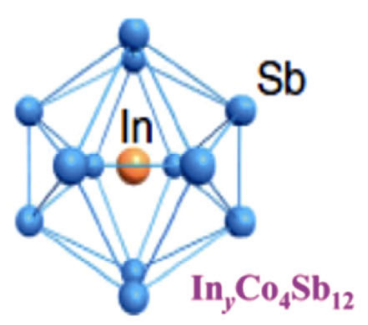

(e) (b)

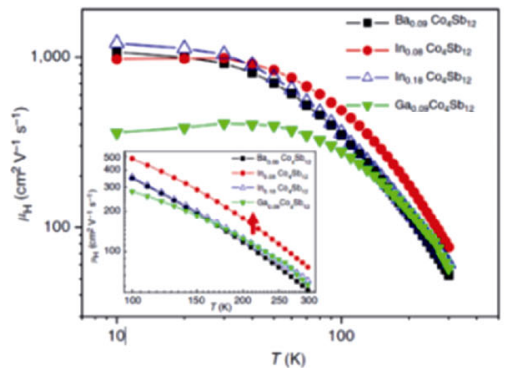

$T(\mathrm{~K})$

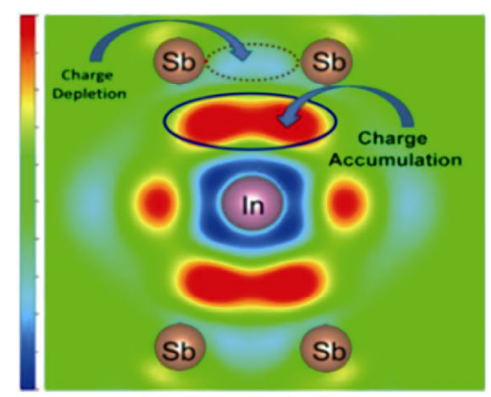

(c)

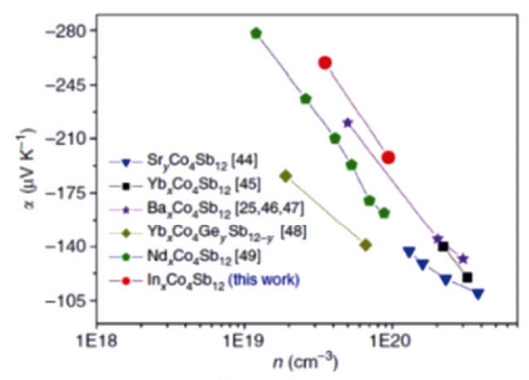

(f)

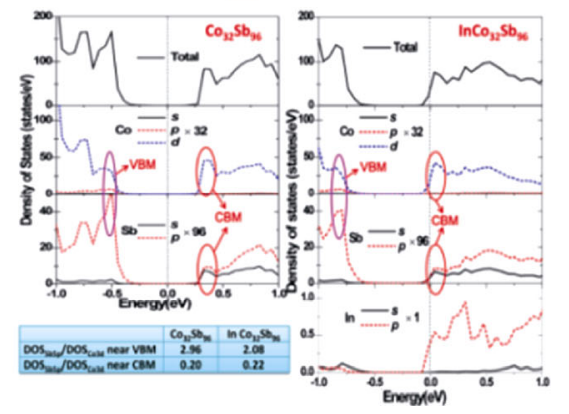

Fig. 16 Synergistic regulation of electrical and thermal transport properties in $\mathrm{In}_{y} \mathrm{Co}_{4} \mathrm{Sb}_{12} \mathrm{TE}$ materials. (a) Temperature dependences of lattice thermal conductivity for $\mathrm{CoSb}_{3}$ and filled $\mathrm{CoSb}_{3}$ in the range of $300-800 \mathrm{~K}$; (b) temperature dependences of Hall mobility for filled $\mathrm{CoSb}_{3}$ in the range of 10-300 K; the inset shows the temperature dependences of Hall mobility for filled $\mathrm{CoSb}_{3}$ in the range of 100-300K; (c) carrier concentration dependences of the Seebeck coefficient of n-type filled $\mathrm{CoSb}_{3}$ at room temperature; (d) filling $\mathrm{Sb}_{12}$ icosahedron voids at the 2a sites; (e) differential charge density of $\operatorname{In}_{0.125} \mathrm{Co}_{4} \mathrm{Sb}_{12}$ projected on the (111) plane; (f) total DOS and partial DOS near VBM and CBM of $\mathrm{CoSb}_{3}$ and $\mathrm{In}_{0.125} \mathrm{Co}_{4} \mathrm{Sb}_{12}$. Reproduced with permission from Ref. [219], (C) Macmillan Publishers Limited 2015.

attention because they have no moving parts and are capable of high power densities, scalable in size, and potentially highly reliable [220]. In order to obtain high conversion efficiency of TE devices, the key factor is that the TE material has high $Z T$ value. The ideal efficiency of thermal to electrical energy conversion for a TE material is expressed as [221]:

$$
\eta=\left(\frac{T_{\mathrm{H}}-T_{\mathrm{C}}}{T_{\mathrm{H}}}\right) \cdot \frac{\sqrt{1+Z T_{\mathrm{avg}}}-1}{\sqrt{1+Z T_{\mathrm{avg}}}+\left(T_{\mathrm{C}} / T_{\mathrm{H}}\right)}
$$

where $T_{\mathrm{H}}$ is the hot-side temperature, $T_{\mathrm{C}}$ is the cold-side temperature, $T_{\text {avg }}=\left(T_{\mathrm{H}}+T_{\mathrm{C}}\right) / 2$ is the arithmetic average of the $T_{\mathrm{H}}$ and $T_{\mathrm{C}}$, and $\Delta T=\left(T_{\mathrm{H}}-T_{\mathrm{C}}\right)$ is the temperature difference. The conversion efficiency is also obtained with Eq. (9) [222]:

$$
\eta=\frac{P}{P+Q_{\mathrm{c}}}=\frac{I V}{I V+Q_{\mathrm{c}}} \times 100 \%
$$

where $P$ is the output power for a given load resistance. The electrical current $(I)$ and the released heat $\left(Q_{\mathrm{c}}\right)$ can be calculated by area integration of the current density or the heat flux over a selected cross section. The terminal voltage $(V)$ can be probed on the cold-side electrode. The maximum output power $\left(P_{\max }\right)$ and the maximum conversion efficiency $\left(\eta_{\max }\right)$ can be determined by applying a parameterized load resistance.

Skutterudite-based TE materials are recognized as the most promising TE materials in the mid-temperature range because they have adequate TE performance and are mechanically robust. Especially, n-type $\mathrm{CoSb}_{3}$-based materials have high $Z T$ values $\left(Z T_{\max } \approx 2.0[7,22,87]\right)$. They are usually used as an ideal n-leg of skutteruditebased TE devices. The structure of a conventional module of TE device follows the $\Pi$-shaped configuration as shown in Fig. 17(a). In addition, there are the tube-shape module (Fig. 17(b)) and Y-shaped configuration (Fig. $17(\mathrm{c}))$. The schematic diagram of a typical $\Pi$-shaped skutterudite-based TE uni-couple is shown in Fig. 17(d). Skutterudite-based TE uni-couple is composed of one n-type skutterudite material, one p-type skutterudite material, intermediate layers, and electrodes. N-type leg or p-type leg has electrodes at both the hot side and the cold side. In order to prevent the diffusion between the skutterudite TE material and the electrode and to release the stress at the joint, an intermediate layer or a barrier layer is usually employed between them. Some attempts 
(a)

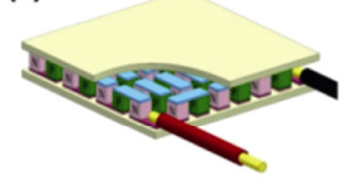

(c)

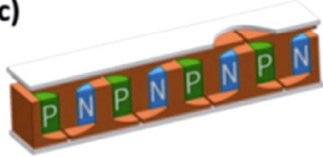

(b)

(d)

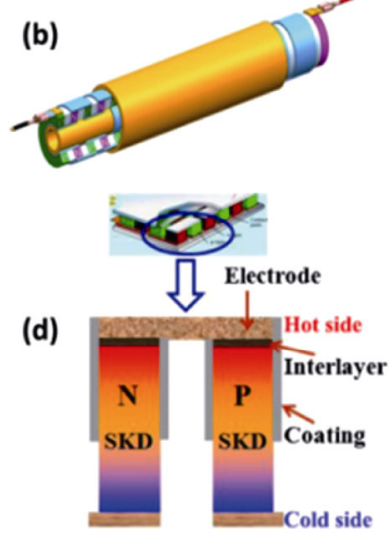

Fig. 17 Schematic diagrams of (a) П-shaped, (b) tube-shaped, and (c) Y-shaped TE module. (d) Schematic diagram of a typical П-shaped skutterudite-based TE uni-couple. Reproduced with permission from Ref. [223], (C) WILEY-VCH Verlag GmbH \& Co. KGaA, Weinheim 2015.

[224-236] have been made to join TE materials onto different electrodes (such as Mo-Cu alloys [225,229,236], $\mathrm{Ag}-\mathrm{Cu}$ [233], $\mathrm{Cu}$ [235]) with different barrier layers or intermediate layer (such as $\mathrm{Cr}-\mathrm{Si}$ alloys [225], Ti-Al alloys [227], Ni [228], Ti [229,230], TiCoSb [231], $\mathrm{ZrO}_{2} / \mathrm{Ti}$ [232], Co [233], Al-Ni [234], Fe-Ni [237]) in recent years. The lower contact resistance, stable interface, and high mechanical properties of the device can be obtained by selecting the appropriate electrode and barrier layers to connect with the $\mathrm{CoSb}_{3}$-based material. In this way, the TE devices can obtain higher output performance and conversion efficiency.

In recent years, some $\mathrm{CoSb}_{3}$-based TE modules (uni-couple [238-241] and multipair [236,237,242-250]) have been widely studied. The output performance and service behavior of $\mathrm{CoSb}_{3}$-based TE devices were greatly improved by the design and optimization of electrode, interface and barrier layer, and the protection coating $[225,232,234,251,252]$ for preventing $\mathrm{Sb}$ sublimation and oxidation. Table 2 summarizes some available $\mathrm{CoSb}_{3}$-based TE devices reported in recent years. Although some progresses have been made in $\mathrm{CoSb}_{3}$-based TE devices, there are still many challenges and technical problems to be solved for further large-scale application.

\section{Conclusions and outlook}

We have reviewed the research progress of $\mathrm{CoSb}_{3}$-based TE materials in recent years. The commonly adopted strategies to reduce the thermal conductivity of $\mathrm{CoSb}_{3}-$ based materials and optimize their TE properties at the atomic-molecular scale and nano-mesoscopic scale were mainly reviewed. Furthermore, the research works of some advanced preparation technologies and synergistic optimization of electrical and thermal transport parameters for $\mathrm{CoSb}_{3}$-based materials were also summarized and analyzed. The research progresses of $\mathrm{CoSb}_{3}$-based TE devices were also briefly summarized in recent years. Although the $Z T$ value of $\mathrm{CoSb}_{3}$-based TE materials has made some progress, however, the conversion efficiency of the TE device corresponding to the $Z T$ value of the material is still low. Therefore, the $Z T$ value of $\mathrm{CoSb}_{3}$-based TE materials still needs to be further improved. At present, some problems in the

Table 2 A summary of the reported $\mathrm{COSb}_{3}$-based $\mathrm{TE}$ devices in recent years

\begin{tabular}{|c|c|c|c|c|c|c|c|c|c|}
\hline Materials of p-legs & Materials of n-legs & Type & $\begin{array}{c}\text { Electrode } \\
\text { of hot } \\
\text { side }\end{array}$ & $\begin{array}{c}\text { Electrode } \\
\text { of cold } \\
\text { side }\end{array}$ & $\begin{array}{c}\text { Barrier } \\
\text { layer }\end{array}$ & $\begin{array}{l}\text { Open-circuit } \\
\text { voltage } \\
(\mathrm{mV})\end{array}$ & $\begin{array}{l}P_{\max } \\
(\mathrm{W})\end{array}$ & $\begin{array}{l}\eta_{\max } \\
(\%)\end{array}$ & $\Delta T\left({ }^{\circ} \mathrm{C}\right)$ Ref. \\
\hline $\mathrm{CeFe}_{3.5} \mathrm{Co}_{0.5} \mathrm{Sb}_{12}$ & $\mathrm{CoSb}_{3}$ & Uni-couple & Metallic & Metallic & None & 204.2 & 0.67 & 10.7 & $27-700 \quad[238]$ \\
\hline $\mathrm{In}_{0.25} \mathrm{Co}_{3} \mathrm{FeSb}_{12}$ & $\mathrm{In}_{0.25} \mathrm{Co}_{3.95} \mathrm{Ni}_{0.05} \mathrm{Sb}_{12}$ & Uni-couple & $\mathrm{Mo}-\mathrm{Cu}$ & $\mathrm{Cu}$ & $\mathrm{Ti}$ & 143 & 0.796 & - & $55-598$ [239] \\
\hline $\mathrm{NdFe}_{3.5} \mathrm{Co}_{0.5} \mathrm{Sb}_{12}$ & $\mathrm{Yb}_{0.35} \mathrm{Co}_{4} \mathrm{Sb}_{12}$ & Uni-couple & $\mathrm{Co}-\mathrm{Si}$ & - & - & - & - & 9.1 & $70-550[240]$ \\
\hline $\mathrm{Yb}_{0.25} \mathrm{Fe}_{0.25} \mathrm{Co}_{3.75} \mathrm{Sb}_{12}$ & $\mathrm{La}_{0.7} \mathrm{Ti}_{0.1} \mathrm{Ga}_{0.1} \mathrm{Fe}_{2.7} \mathrm{Co}_{1.3} \mathrm{Sb}_{12}$ & Uni-couple & Mo & $\mathrm{Cu}$ & $\mathrm{Ga}-\mathrm{Sn}$ & 80 & 0.337 & 7.2 & $40-406[241]$ \\
\hline $\mathrm{Ce}_{0.45} \mathrm{Co}_{2.5} \mathrm{Fe}_{1.5} \mathrm{Sb}_{12}$ & $\mathrm{Yb}_{0.25} \mathrm{Co}_{4} \mathrm{Sb}_{12} / \mathrm{Yb}_{2} \mathrm{O}_{3}$ & 2 pairs & $\mathrm{Mo}-\mathrm{Cu}$ & $\mathrm{Cu}$ & Mo & 210 & 0.14 & 6.4 & $47-540[242]$ \\
\hline $\mathrm{Ce}_{0.9} \mathrm{Fe}_{3} \mathrm{CoSb}_{12}$ & $\mathrm{Yb}_{0.3} \mathrm{Co}_{4} \mathrm{Sb}_{12} / \mathrm{MWCNTs}$ & 8 pairs & $\mathrm{Mo}-\mathrm{Cu}$ & $\mathrm{Cu}$ & $\mathrm{Ag}-\mathrm{Cu}-\mathrm{Zn}$ & 1480 & 0.46 & 9.3 & $41-499[243]$ \\
\hline $\mathrm{DD}_{y} \mathrm{Fe}_{3} \mathrm{CoSb}_{12}$ & $(\mathrm{Mm}, \mathrm{Sm})_{y} \mathrm{Co}_{4} \mathrm{Sb}_{12}$ & 8 pairs & Metallic & Metallic & $\mathrm{Fe}-\mathrm{Ni}$ alloy & - & 0.806 & - & $30-600[237]$ \\
\hline $\mathrm{CeFe}_{3} \mathrm{CoSb}_{12}$ & $\mathrm{Yb}_{0.15} \mathrm{Co}_{4} \mathrm{Sb}_{12}$ & 14 pairs & $\mathrm{Ag}$ & $\mathrm{Ag}$ & $\mathrm{Ag}-\mathrm{Pd}$ & $\sim 520$ & 0.48 & - & $20-300[244]$ \\
\hline$(\mathrm{La}, \mathrm{Ba}, \mathrm{Ga}, \mathrm{Ti})_{0.9} \mathrm{Fe}_{3} \mathrm{CoSb}_{12}$ & $(\mathrm{Yb}, \mathrm{Ca}, \mathrm{Al}, \mathrm{Ga}, \mathrm{In})_{0.7} \mathrm{Fe}_{0.25} \mathrm{Co}_{3.75} \mathrm{Sb}_{12}$ & 32 pairs & AlN & AlN & - & $\sim 400$ & 25 & 8.5 & $50-600[245]$ \\
\hline $\mathrm{Yb}_{0.72} \mathrm{Co}_{4} \mathrm{Sb}_{12} / 1.4 \mathrm{vol} \% \mathrm{rGO}$ & $\mathrm{Ce}_{0.85} \mathrm{Fe}_{3} \mathrm{CoSb}_{12} / 0.72 \mathrm{vol} \% \mathrm{rGO}$ & 8 pairs & $\mathrm{Mo}-\mathrm{Cu}$ & $\mathrm{Cu}$ & $\mathrm{Ag}-\mathrm{Cu}-\mathrm{Zn}$ & - & 3.8 & 8.4 & $23-600[246]$ \\
\hline $\mathrm{La}_{0.8} \mathrm{Ba}_{0.01} \mathrm{Ga}_{0.1} \mathrm{Ti}_{0.1} \mathrm{Fe}_{3} \mathrm{CoSb}_{12}$ & $\mathrm{La}_{0.3} \mathrm{Ca}_{0.1} \mathrm{Al}_{0.1} \mathrm{Ga}_{0.1} \mathrm{In}_{0.2} \mathrm{Co}_{3.75} \mathrm{Fe}_{0.25} \mathrm{Sb}_{12}$ & 32 pairs & - & - & - & 4920 & 32 & 8 & $50-600 \quad[248]$ \\
\hline $\mathrm{Mm}_{0.30} \mathrm{Fe}_{1.46} \mathrm{Co}_{2.54} \mathrm{Sb}_{12.05}$ & $\mathrm{Yb}_{0.09} \mathrm{Ba}_{0.05} \mathrm{La}_{0.05} \mathrm{Co}_{4} \mathrm{Sb}_{12}$ & 32 pairs & Metallic & Metallic & Mo & 2.73 & 10.5 & 7 & $40-500 \quad[249]$ \\
\hline
\end{tabular}


research of $\mathrm{CoSb}_{3}$-based TE materials, such as the optimization and decoupling of thermal and electrical transport properties, and the development of preparation technology, need to be further studied.

(i) For $\mathrm{CoSb}_{3}$-based materials with the filling atom, although there have been a lot of reports on the optimization of the number of filling atoms, the filling fraction, and the type of filling atoms. However, it is still possible to reduce the thermal conductivity of the $\mathrm{CoSb}_{3}$ material by further optimizing these parameters to improve the TE performance. (ii) The TE properties of $\mathrm{CoSb}_{3}$-based materials can be significantly improved by forming solid solution alloy or the filling of the foreign atoms in the $\mathrm{Sb}_{12}$ icosahedron void. It is expected to further improve the TE properties of $\mathrm{CoSb}_{3}$-based materials by doping and filling with foreign atoms simultaneously. (iii) The introduction of nanoparticles, special structures, and low-dimensional nanocrystallization in $\mathrm{CoSb}_{3}$-based materials can obvious increase their TE properties and even mechanical properties. We may further screen the types of the introduced nanoparticles and special structures, and study the effects of these nanoparticles and special structures on the TE properties and mechanical properties of $\mathrm{CoSb}_{3}$-based materials in order to further improve their TE and mechanical performance. Besides, miniaturization of devices is the trend of development; therefore, it is very important to prepare high-performance low-dimensional $\mathrm{CoSb}_{3}$-based materials. (v) It is a challenge to decouple the electrical and thermal transport properties of $\mathrm{CoSb}_{3}$-based materials because the TE parameters are closely related to each other and mutually constrained. The decoupling and synergistic optimizations of the electrical and thermal transport properties for $\mathrm{CoSb}_{3}$-based materials have been achieved through some new effects. However, the physical mechanisms resulting from these new effects still need to be studied further. (vi) For the preparation of $\mathrm{CoSb}_{3}$-based materials, researchers have reported some advanced preparation techniques, which provide the possibility for large-scale preparation of $\mathrm{CoSb}_{3}$-based materials. More advanced preparation techniques can still be explored to further shorten the preparation time and reduce the preparation cost of the materials, improving the properties of the prepared materials. (vii) The conversion efficiency of $\mathrm{CoSb}_{3}$-based TE devices needs to be further improved, and the module manufacturing cost needs to be further reduced by scaling up and process optimization; the service behavior of $\mathrm{CoSb}_{3}$-based TE devices under complex operating conditions should be further studied in detail.

In short, there is still much work to be done to further improve the TE properties of both $\mathrm{CoSb}_{3}$-based materials and devices. Although the challenges are pervasive, the research of $\mathrm{CoSb}_{3}$-based TE materials is becoming an intense and worldwide activity. More and more researchers are attracted to the field of TE materials. Interdisciplinary communication between physicists, chemists, materials scientists, and device engineers is also deepening. The interdisciplinary research of TE materials and other subjects is more and more extensive. It is expected to promote the sustained and rapid growth of TE research and future large-scale application.

\section{Acknowledgements}

The present work was supported by the National Natural Science Foundation of China (Grant No. 51872006), High Level Doctoral Talent Program of Anhui University of Technology (DT17200008), and National Undergraduate Training Programs for Innovation and Entrepreneurship (No. S201910360186).

\section{References}

[1] Bell LE. Cooling, heating, generating power, and recovering waste heat with thermoelectric systems. Science 2008, 321: 1457-1461.

[2] Snyder GJ, Toberer ES. Complex thermoelectric materials. Nat Mater 2008, 7: 105-114.

[3] Stiewe C, Ebling D, Müller E. Application potential of thermoelectric generators for waste heat recovery in stationary systems. Gefahrst Reinhalt L 2017, 77: 502506.

[4] Schierning G, Chavez R, Schmechel R, et al. Concepts for medium-high to high temperature thermoelectric heat-toelectricity conversion: A review of selected materials and basic considerations of module design. Transl Mater Res 2015, 2: 025001.

[5] Liu WS, Zhang BP, Li JF, et al. Enhanced thermoelectric properties in $\mathrm{CoSb}_{3-x} \mathrm{Te}_{x}$ alloys prepared by mechanical alloying and spark plasma sintering. J Appl Phys 2007, 102: 103717.

[6] Sales BC, Mandrus D, Williams RK. Filled skutterudite antimonides: A new class of thermoelectric materials. Science 1996, 272: 1325-1328.

[7] Shi X, Yang J, Salvador JR, et al. Multiple-filled skutterudites: High thermoelectric figure of merit through separately optimizing electrical and thermal transports. $J$ Am Chem Soc 2011, 133: 7837-7846.

[8] Li H, Tang XF, Su XL, et al. Preparation and thermoelectric 
properties of high-performance $\mathrm{Sb}$ additional $\mathrm{Yb}_{0.2} \mathrm{Co}_{4} \mathrm{Sb}_{12+y}$ bulk materials with nanostructure. Appl Phys Lett 2008, 92: 202114.

[9] Siemens ME, Li Q, Yang RG, et al. Quasi-ballistic thermal transport from nanoscale interfaces observed using ultrafast coherent soft X-ray beams. Nat Mater 2010, 9: 26-30.

[10] Zhao WY, Liang Z, Wei P, et al. Enhanced thermoelectric performance via randomly arranged nanopores: Excellent transport properties of $\mathrm{YbZn}_{2} \mathrm{Sb}_{2}$ nanoporous materials. Acta Mater 2012, 60: 1741-1746.

[11] Liu H, Shi X, Xu F, et al. Copper ion liquid-like thermoelectrics. Nat Mater 2012, 11: 422-425.

[12] Delaire O, Ma J, Marty K, et al. Giant anharmonic phonon scattering in PbTe. Nat Mater 2011, 10: 614-619.

[13] Liu W, Tan XJ, Yin K, et al. Convergence of conduction bands as a means of enhancing thermoelectric performance of $n$-type $\mathrm{Mg}_{2} \mathrm{Si}_{1-x} \mathrm{Sn}_{x}$ solid solutions. Phys Rev Lett 2012, 108: 166601 .

[14] Pei YZ, Shi XY, LaLonde A, et al. Convergence of electronic bands for high performance bulk thermoelectrics. Nature 2011, 473: 66-69.

[15] Tan GJ, Zeier WG, Shi FY, et al. High thermoelectric performance $\mathrm{SnTe}-\mathrm{In}_{2} \mathrm{Te}_{3}$ solid solutions enabled by resonant levels and strong vacancy phonon scattering. Chem Mater 2015, 27: 7801-7811.

[16] Rhyee JS, Lee KH, Lee SM, et al. Peierls distortion as a route to high thermoelectric performance in $\mathrm{In}_{4} \mathrm{Se}_{3-\delta}$ crystals. Nature 2009, 459: 965-968.

[17] Heremans JP, Jovovic V, Toberer ES, et al. Enhancement of thermoelectric efficiency in PbTe by distortion of the electronic density of states. Science 2008, 321: 554-557.

[18] Ahmad S, Hoang K, Mahanti SD. Ab initio study of deep defect states in narrow band-gap semiconductors: Group III impurities in PbTe. Phys Rev Lett 2006, 96: 056403.

[19] Zhao LD, Tan GJ, Hao SQ, et al. Ultrahigh power factor and thermoelectric performance in hole-doped single-crystal SnSe. Science 2016, 315: 141-144.

[20] Zhou J, Yang RG, Chen G, et al. Optimal bandwidth for high efficiency thermoelectrics. Phys Rev Lett 2011, 107: 226601.

[21] Zhao W, Liu ZY, Wei P, et al. Magnetoelectric interaction and transport behaviours in magnetic nanocomposite thermoelectric materials. Nat Nanotech 2017, 12: 55-60.

[22] Zhao WY, Liu ZY, Sun ZG, et al. Superparamagnetic enhancement of thermoelectric performance. Nature 2017, 549: 247-251.

[23] Wu D, Zhao LD, Tong X, et al. Superior thermoelectric performance in $\mathrm{PbTe}-\mathrm{PbS}$ pseudo-binary: Extremely low thermal conductivity and modulated carrier concentration. Energy Environ Sci 2015, 8: 2056-2068.

[24] Lee Y, Lo SH, Androulakis J, et al. High-performance tellurium-free thermoelectrics: All-scale hierarchical structuring of p-type $\mathrm{PbSe}-\mathrm{MSe}$ systems $(\mathrm{M}=\mathrm{Ca}, \mathrm{Sr}, \mathrm{Ba})$. $J$ Am Chem Soc 2013, 135: 5152-5160.
[25] Zhao LD, He JQ, Hao SQ, et al. Raising the thermoelectric performance of p-type $\mathrm{PbS}$ with endotaxial nanostructuring and valence-band offset engineering using CdS and ZnS. J Am Chem Soc 2012, 134: 16327-16336.

[26] Biswas K, He JQ, Blum ID, et al. High-performance bulk thermoelectrics with all-scale hierarchical architectures. Nature 2012, 489: 414-418.

[27] Zhao LD, Hao SQ, Lo SH, et al. High thermoelectric performance via hierarchical compositionally alloyed nanostructures. J Am Chem Soc 2013, 135: 7364-7370.

[28] Sharp JW, Jones EC, Williams RK, et al. Thermoelectric properties of $\mathrm{CoSb}_{3}$ and related alloys. J Appl Phys 1995, 78: 1013-1018.

[29] Rogl G, Rogl P. Skutterudites, a most promising group of thermoelectric materials. Curr Opin Green Sustain Chem 2017, 4: 50-57.

[30] Zhou XY, Yan YC, Lu X, et al. Routes for high-performance thermoelectric materials. Mater Today 2018, 21: 974-988.

[31] Mei ZG, Yang J, Pei YZ, et al. Alkali-metal-filled $\mathrm{CoSb}_{3}$ skutterudites as thermoelectric materials: Theoretical study. Phys Rev B 2008, 77: 045202.

[32] Lu PX, Ma QH, Li Y, et al. A study of electronic structure and lattice dynamics of $\mathrm{CoSb}_{3}$ skutterudite. J Magn Magn Mater 2010, 322: 3080-3083.

[33] Sofo JO, Mahan GD. Electronic structure and transport properties of $\mathrm{CoSb}_{3}$ : A narrow band-gap semiconductor. MRS Proc 1998, 545: 315.

[34] Tang YL, Gibbs ZM, Agapito LA, et al. Convergence of multi-valley bands as the electronic origin of high thermoelectric performance in $\mathrm{CoSb}_{3}$ skutterudites. Nat Mater 2015, 14: 1223-1228.

[35] Caillat T, Borshchevsky A, Fleurial JP. Properties of single crystalline semiconducting $\mathrm{CoSb}_{3}$. J Appl Phys 1996, 80: 4442-4449.

[36] Ioffe AV, Ioffe AF. Thermal conductivity of semiconductors. Izv Akad Nauk SSSR Ser Fiz 1956, 20: 65-72.

[37] Pekar SI. Auto-localization of the electron in a dielectric inertially polarizing medium. Zh Eksp Teor Fiz 1946, 16: 335.

[38] Fröhlich H. Electrons in lattice fields. Adv Phys 1954, 3: 325-361.

[39] Alexandrov AS. Lattice polarons and switching in molecular nanowires and quantum dots. In: Nanotechnology for Electronic Materials and Devices. Boston, MA, USA: Springer US, 2007: 305-356.

[40] Kim H, Kim MH, Kaviany M. Lattice thermal conductivity of $\mathrm{UO}_{2}$ usingab-initio and classical molecular dynamics. $J$ Appl Phys 2014, 115: 123510.

[41] Callaway J. Model for lattice thermal conductivity at low temperatures. Phys Rev 1959, 113: 1046-1051.

[42] Xie HH, Wang H, Pei YZ, et al. Beneficial contribution of alloy disorder to electron and phonon transport in half-heusler thermoelectric materials. Adv Funct Mater 2013, 23: 5123-5130. 
[43] Fu CG, Zhu TJ, Liu YT, et al. Band engineering of high performance p-type FeNbSb based half-Heusler thermoelectric materials for figure of merit $z T>1$. Energy Environ Sci 2015, 8: 216-220.

[44] Fu CG, Xie HH, Zhu TJ, et al. Enhanced phonon scattering by mass and strain field fluctuations in $\mathrm{Nb}$ substituted FeVSb half-Heusler thermoelectric materials. J Appl Phys 2012, 112: 124915.

[45] Ziman JM. XVII. The effect of free electrons on lattice conduction. Philos Mag 1956, 1: 191-198.

[46] Parrott JE. Heat conduction mechanisms in semiconducting materials. Rev Int Hautes Temp Refract 1979, 16: 393-403.

[47] Anno H, Matsubara K, Notohara Y, et al. Effects of doping on the transport properties of $\mathrm{CoSb}_{3}$. J Appl Phys 1999, 86: 3780-3786.

[48] Shi X, Zhou Z, Zhang W, et al. Solid solubility of Ir and Rh at the Co sites of skutterudites. J Appl Phys 2007, 101: 123525.

[49] Zhou ZH, Uher C, Jewell A, et al. Influence of point-defect scattering on the lattice thermal conductivity of solid solution $\operatorname{Co}\left(\mathrm{Sb}_{1-x} \mathrm{As}_{x}\right)_{3}$. Phys Rev $B$ 2005, 71: 235209.

[50] Xu CL, Duan B, Ding SJ, et al. Thermoelectric transport properties of nickel-doped $\mathrm{Co}_{4-x} \mathrm{Ni}_{x} \mathrm{Sb}_{11.6} \mathrm{Te}_{0.2} \mathrm{Se}_{0.2}$ skutterudites. Physica B 2013, 425: 34-37.

[51] Kajikawa Y. Multi-band analysis of thermoelectric properties of $n$-type $\mathrm{Co}_{1-x} \mathrm{Ni}_{x} \mathrm{Sb}_{3}(0 \leqslant x \leqslant 0.01)$ over a wide temperature range of 10-773 K. J Alloys Compd 2016, 664: 338-350.

[52] Alleno E, Zehani E, Gaborit M, et al. Mesostructured thermoelectric $\mathrm{Co}_{1-y} \mathrm{M}_{y} \mathrm{Sb}_{3}(\mathrm{M}=\mathrm{Ni}, \mathrm{Pd})$ skutterudites. $J$ Alloys Compd 2017, 692: 676-686.

[53] Kim IH, Ur SC. Electronic transport properties of Fe-doped $\mathrm{CoSb}_{3}$ prepared by encapsulated induction melting. Mater Lett 2007, 61: 2446-2450.

[54] Katsuyama S, Shichijo Y, Ito M, et al. Thermoelectric properties of the skutterudite $\mathrm{Co}_{1-x} \mathrm{Fe}_{x} \mathrm{Sb}_{3}$ system. J Appl Phys 1998, 84: 6708-6712.

[55] Kim IH, Ur SC. Electronic transport properties of Ni-doped $\mathrm{CoSb}_{3}$ prepared by encapsulated induction melting. Met Mater Int 2007, 13: 53-58.

[56] Li XY, Chen LD, Fan JF, et al. Thermoelectric properties of Te-doped $\mathrm{CoSb}_{3}$ by spark plasma sintering. J Appl Phys 2005, 98: 083702.

[57] Deng L, Ma HA, Su TC, et al. Enhanced thermoelectric properties in $\mathrm{Co}_{4} \mathrm{Sb}_{12-x} \mathrm{Te}_{x}$ alloys prepared by HPHT. Mater Lett 2009, 63: 2139-2141.

[58] Koyanagi T, Tsubouchi T, Ohtani M, et al. Thermoelectric properties of $\mathrm{Co}\left(\mathrm{M}_{x} \mathrm{Sb}_{1-x}\right)_{3}(\mathrm{M}=\mathrm{Ge}, \mathrm{Sn}, \mathrm{Pb})$ compounds. In: Proceedings of the 15th International Conference on Thermoelectrics, 1996: 107-111.

[59] $\mathrm{Su} \mathrm{XL}$, Li H, Yan $\mathrm{YG}$, et al. Microstructure and thermoelectric properties of $\mathrm{CoSb}_{2.75} \mathrm{Ge}_{0.25-x} \mathrm{Te}_{x}$ prepared by rapid solidification. Acta Mater 2012, 60: 3536-3544.

[60] Su XL, Li H, Wang GY, et al. Structure and transport properties of double-doped $\mathrm{CoSb}_{2.75} \mathrm{Ge}_{0.25-x} \mathrm{Te}_{x} \quad(x=$ 0.125-0.20) with in situ nanostructure. Chem Mater 2011, 23: 2948-2955.

[61] Yan YG, Ke HQ, Yang JH, et al. Fabrication and thermoelectric properties of n-type $\mathrm{CoSb}_{2.85} \mathrm{Te}_{0.15}$ using selective laser melting. ACS Appl Mater Interfaces 2018, 10: 13669-13674.

[62] Jiang YP, Jia XP, Ma H. The thermoelectric properties of $\mathrm{CoSb}_{3}$ compound doped with $\mathrm{Te}$ and $\mathrm{Sn}$ synthesized at different pressure. Mod Phys Lett B 2017, 31: 1750261.

[63] Dahal T, Lan YC, Jie Q, et al. Substitution of antimony by tin and tellurium in n-type skutterudites $\mathrm{CoSb}_{2.8} \mathrm{Sn}_{x} \mathrm{Te}_{0.2-x}$. JOM 2014, 66: 2282-2287.

[64] Alleno E, Zehani E, Rouleau O. Metallurgical and thermoelectric properties in $\mathrm{Co}_{1-x} \mathrm{Pd}_{x} \mathrm{Sb}_{3}$ and $\mathrm{Co}_{1-x} \mathrm{Ni}_{x} \mathrm{Sb}_{3}$ revisited. J Alloys Compd 2013, 572: 43-48.

[65] Bouhafs C, Chitroub M, Scherrer H. Synthesis and thermoelectric characterizations of $\mathrm{Pd}$ and Se-doped skutterudite compound. J Mater Sci: Mater Electron 2018, 29: $1264-1268$.

[66] Dong JY, Yang K, Xu B, et al. Structure and thermoelectric properties of Se- and $\mathrm{Se} / \mathrm{Te}$-doped $\mathrm{CoSb}_{3}$ skutterudites synthesized by high-pressure technique. $J$ Alloys Compd 2015, 647: 295-302.

[67] Zhang Q, Li XH, Kang YL, et al. High pressure synthesis of Te-doped $\mathrm{CoSb}_{3}$ with enhanced thermoelectric performance. J Mater Sci: Mater Electron 2015, 26: 385-391.

[68] Sun HR, Jia XP, Deng L, et al. Beneficial effect of high pressure and double-atom-doped skutterudite compounds $\mathrm{Co}_{4} \mathrm{Sb}_{11.5-x} \mathrm{Te}_{0.5} \mathrm{Sn}_{x}$ by HPHT. J Alloys Compd 2014, 612: $16-19$.

[69] Sun HR, Jia XP, Deng L, et al. Effect of HPHT processing on the structure, and thermoelectric properties of $\mathrm{Co}_{4} \mathrm{Sb}_{12}$ co-doped with Te and Sn. J Mater Chem A 2015, 3: 4637-4641.

[70] Han X, Wang LB, Li DN, et al. Effects of pressure and ions doping on the optimization of double filled $\mathrm{CoSb}_{3}$ thermoelectric materials. Mater Lett 2019, 237: 49-52.

[71] Kruszewski MJ, Zybała R, Ciupiński, et al. Microstructure and thermoelectric properties of bulk cobalt antimonide $\left(\mathrm{CoSb}_{3}\right)$ skutterudites obtained by pulse plasma sintering. J Electron Mater 2016, 45: 1369-1376.

[72] Le Tonquesse S, Alleno É, Demange V, et al. Innovative synthesis of mesostructured $\mathrm{CoSb}_{3}$-based skutterudites by magnesioreduction. J Alloys Compd 2019, 796: 176-184.

[73] Lei Y, Gao WS, Zheng R, et al. Ultrafast synthesis of Te-doped $\mathrm{CoSb}_{3}$ with excellent thermoelectric properties. ACS Appl Energy Mater 2019, 2: 4477-4485.

[74] Nolas GS, Kaeser M, Littleton RT, et al. High figure of merit in partially filled ytterbium skutterudite materials. Appl Phys Lett 2000, 77: 1855-1857.

[75] Chen LD, Kawahara T, Tang XF, et al. Anomalous barium filling fraction and n-type thermoelectric performance of $\mathrm{Ba}_{y} \mathrm{Co}_{4} \mathrm{Sb}_{12}$. J Appl Phys 2001, 90: 1864-1868. 
[76] Shi X, Kong H, Li CP, et al. Low thermal conductivity and high thermoelectric figure of merit in n-type $\mathrm{Ba}_{x} \mathrm{Yb}_{y} \mathrm{Co}_{4} \mathrm{Sb}_{12}$ double-filled skutterudites. Appl Phys Lett 2008, 92: 182101.

[77] Zhao WY, Wei P, Zhang QJ, et al. Enhanced thermoelectric performance in Barium and indium double-filled skutterudite bulk materials via orbital hybridization induced by indium filler. J Am Chem Soc 2009, 131: 3713-3720.

[78] Li H, Tang XF, Zhang QJ, et al. High performance $\mathrm{In}_{x} \mathrm{Ce}_{y} \mathrm{Co}_{4} \mathrm{Sb}_{12}$ thermoelectric materials with in situ forming nanostructured InSb phase. Appl Phys Lett 2009, 94: 102114.

[79] Bai SQ, Huang XY, Chen LD, et al. Thermoelectric properties of n-type $\mathrm{Sr}_{x} \mathrm{M}_{y} \mathrm{Co}_{4} \mathrm{Sb}_{12}(\mathrm{M}=\mathrm{Yb}, \mathrm{Ba})$ double-filled skutterudites. Appl Phys A 2010, 100: 1109-1114.

[80] Salvador JR, Yang J, Wang $\mathrm{H}$, et al. Double-filled skutterudites of the type $\mathrm{Yb}_{x} \mathrm{Ca}_{y} \mathrm{Co}_{4} \mathrm{Sb}_{12}$ : Synthesis and properties. J Appl Phys 2010, 107: 043705.

[81] Wei P, Zhao WY, Dong CL, et al. Excellent performance stability of $\mathrm{Ba}$ and In double-filled skutterudite thermoelectric materials. Acta Mater 2011, 59: 3244-3254.

[82] Zhang JJ, Xu B, Wang LM, et al. Great thermoelectric power factor enhancement of $\mathrm{CoSb}_{3}$ through the lightest metal element filling. Appl Phys Lett 2011, 98: 072109.

[83] $\mathrm{Su} \mathrm{XL}$, Li H, Yan YG, et al. The role of $\mathrm{Ga}$ in $\mathrm{Ba}_{0.30} \mathrm{Ga}_{x} \mathrm{Co}_{4} \mathrm{Sb}_{12+x}$ filled skutterudites. $J$ Mater Chem 2012, 22: 15628-15634.

[84] Zhang JJ, Xu B, Wang LM, et al. High-pressure synthesis of phonon-glass electron-crystal featured thermoelectric $\mathrm{Li}_{x} \mathrm{Co}_{4} \mathrm{Sb}_{12}$. Acta Mater 2012, 60: 1246-1251.

[85] Deng L, Jia XP, Ma HA, et al. The thermoelectric properties of $\operatorname{In}_{x} \mathrm{M}_{0.2} \mathrm{Co}_{4} \mathrm{Sb}_{12}(\mathrm{M}=\mathrm{Ba}$ and $\mathrm{Pb})$ double-filled skutterudites. Solid State Commun 2013, 163: 15-18.

[86] Qiu PF, Shi X, Qiu YT, et al. Enhancement of thermoelectric performance in slightly charge-compensated $\mathrm{Ce}_{y} \mathrm{Co}_{4} \mathrm{Sb}_{12}$ skutterudites. Appl Phys Lett 2013, 103: 062103.

[87] Rogl G, Grytsiv A, Rogl P, et al. N-type skutterudites (R, $\mathrm{Ba}, \mathrm{Yb})_{y} \mathrm{Co}_{4} \mathrm{Sb} 12(\mathrm{R}=\mathrm{Sr}, \mathrm{La}, \mathrm{Mm}, \mathrm{DD}, \mathrm{SrMm}, \mathrm{SrDD})$ approaching ZT 2.0. Acta Mater 2014, 63: 30-43.

[88] Tang YL, Qiu YT, Xi LL, et al. Phase diagram of In-Co-Sb system and thermoelectric properties of In-containing skutterudites. Energy Environ Sci 2014, 7: 812-819.

[89] Rogl G, Grytsiv A, Yubuta K, et al. In-doped multifilled $n$-type skutterudites with $Z T=1.8$. Acta Mater 2015, 95: 201-211.

[90] Li YL, Qiu PF, Duan HZ, et al. Enhanced thermoelectric performance in rare-earth filled-skutterudites. $J$ Mater Chem C 2016, 4: 4374-4379.

[91] Wang SY, Salvador JR, Yang J, et al. High-performance $n$-type $\mathrm{Yb}_{x} \mathrm{Co}_{4} \mathrm{Sb}_{12}$ : From partially filled skutterudites towards composite thermoelectrics. NPG Asia Mater 2016, 8: e285.

[92] Khovaylo VV, Korolkov TA, Voronin AI, et al. Rapid preparation of $\operatorname{In}_{x} \mathrm{Co}_{4} \mathrm{Sb}_{12}$ with a record-breaking $Z T=1.5$ :
The role of the In overfilling fraction limit and $\mathrm{Sb}$ over stoichiometry. J Mater Chem A 2017, 5: 3541-3546.

[93] Wang LB, Deng L, Qin JM, et al. Enhanced thermoelectric properties of double-filled $\mathrm{CoSb}_{3}$ via high-pressure regulating. Inorg Chem 2018, 57: 6762-6766.

[94] Lee S, Lee KH, Kim YM, et al. Simple and efficient synthesis of nanograin structured single phase filled skutterudite for high thermoelectric performance. Acta Mater 2018, 142: 8-17.

[95] Li WJ, Wang J, Xie YT, et al. Enhanced thermoelectric performance of $\mathrm{Yb}$-single-filled skutterudite by ultralow thermal conductivity. Chem Mater 2019, 31: 862-872.

[96] Ryll B, Schmitz A, de Boor J, et al. Structure, phase composition, and thermoelectric properties of $\mathrm{Yb}_{x} \mathrm{Co}_{4} \mathrm{Sb}_{12}$ and their dependence on synthesis method. ACS Appl Energy Mater 2018, 1: 113-122.

[97] Leszczynski J, Ros VD, Lenoir B, et al. Electronic band structure, magnetic, transport and thermodynamic properties of In-filled skutterudites $\operatorname{In}_{x} \mathrm{Co}_{4} \mathrm{Sb}_{12}$. J Phys D: Appl Phys 2013, 46: 495106.

[98] He T, Chen JZ, Rosenfeld HD, et al. Thermoelectric properties of indium-filled skutterudites. Chem Mater 2006, 18: 759-762.

[99] Mallik RC, Stiewe C, Karpinski G, et al. Thermoelectric properties of $\mathrm{Co}_{4} \mathrm{Sb}_{12}$ skutterudite materials with partial in filling and excess in additions. J Electron Mater 2009, 38: 1337-1343.

[100] Visnow E, Heinrich CP, Schmitz A, et al. On the true indium content of in-filled skutterudites. Inorg Chem 2015, 54: 7818-7827.

[101] Leszczyński J, Szczypka W, Candolfi C, et al. HPHT synthesis of highly doped $\mathrm{In}_{x} \mathrm{Co}_{4} \mathrm{Sb}_{12}$-Experimental and theoretical study. J Alloys Compd 2017, 727: 1178-1188.

[102] Benyahia M, Ohorodniichuk V, Leroy E, et al. High thermoelectric figure of merit in mesostructured $\mathrm{In}_{0.25} \mathrm{Co}_{4} \mathrm{Sb}_{12}$-type skutterudite. J Alloys Compd 2018, 735: 1096-1104.

[103] Gainza J, Serrano-Sánchez F, Prado-Gonjal J, et al. Substantial thermal conductivity reduction in mischmetal skutterudites $\mathrm{Mm}_{x} \mathrm{Co}_{4} \mathrm{Sb}_{12}$ prepared under high-pressure conditions, due to uneven distribution of the rare-earth elements. J Mater Chem C 2019, 7: 4124-4131.

[104] Matsubara M, Masuoka Y, Asahi R. Effects of doping IIIB elements $(\mathrm{Al}, \mathrm{Ga}, \mathrm{In})$ on thermoelectric properties of nanostructured n-type filled skutterudite compounds. $J$ Alloys Compd 2019, 774: 731-738.

[105] Le Tonquesse S, Alleno, Demange V, et al. Reaction mechanism and thermoelectric properties of $\mathrm{In}_{0 \cdot 22} \mathrm{Co}_{4} \mathrm{Sb}_{12}$ prepared by magnesiothermy. Mater Today Chem 2020, 16: 100223 .

[106] Bashir MBA, Mohd Sabri MF, Said SM, et al. Enhancement of thermoelectric properties of $\mathrm{Co}_{4} \mathrm{Sb}_{12}$ skutterudite by $\mathrm{Al}$ and $\mathrm{La}$ double filling. $J$ Solid State Chem 2020, 284: 121205.

[107] Zhang SY, Xu SW, Gao H, et al. Characterization of 
multiple-filled skutterudites with high thermoelectric performance. J Alloys Compd 2020, 814: 152272.

[108] Duan B, Yang J, Salvador JR, et al. Electronegative guests in $\mathrm{CoSb}_{3}$. Energy Environ Sci 2016, 9: 2090-2098.

[109] Ortiz BR, Crawford CM, McKinney RW, et al. Thermoelectric properties of bromine filled $\mathrm{CoSb}_{3}$ skutterudite. J Mater Chem A 2016, 4: 8444-8450.

[110] Li JL, Duan B, Yang HJ, et al. Thermoelectric properties of electronegatively filled $\mathrm{S}_{y} \mathrm{Co}_{4-x} \mathrm{Ni}_{x} \mathrm{Sb}_{12}$ skutterudites. $J$ Mater Chem C 2019, 7: 8079-8085.

[111] Wang HT, Duan B, Bai GH, et al. Beneficial effect of S-filling on thermoelectric properties of $\mathrm{S}_{x} \mathrm{Co}_{4} \mathrm{Sb}_{11.2} \mathrm{Te}_{0.8}$ skutterudite. J Electron Mater 2018, 47: 3061-3066.

[112] Shi X, Zhang W, Chen LD, et al. Filling fraction limit for intrinsic voids in crystals: Doping in skutterudites. Phys Rev Lett 2005, 95: 185503.

[113] Morelli DT, Meisner GP. Low temperature properties of the filled skutterudite $\mathrm{CeFe}_{4} \mathrm{Sb}_{12}$. J Appl Phys 1995, 77: 3777-3781.

[114] Jeitschko W, Braun D. $\mathrm{LaFe}_{4} \mathrm{P}_{12}$ with filled $\mathrm{CoAs}_{3}$-type structure and isotypic lanthanoid-transition metal polyphosphides. Acta Crystallogr Sect B 1977, 33: 3401-3406.

[115] Slack GA. CRC Handbook of Thermoelectric. Boca Raton: CRC Press, 1995: 407-440.

[116] Puyet M, Dauscher A, Lenoir B, et al. Influence of Ni on the thermoelectric properties of the partially filled calcium skutterudites $\mathrm{Ca}_{y} \mathrm{Co}_{4-x} \mathrm{Ni}_{x} \mathrm{Sb}_{12}$. Phys Rev $B$ 2007, 75: 245110.

[117] Trivedi V, Battabyal M, Balasubramanian $\mathrm{P}$, et al. Microstructure and doping effect on the enhancement of the thermoelectric properties of Ni doped Dy filled $\mathrm{CoSb}_{3}$ skutterudites. Sustain Energy Fuels 2018, 2: 2687-2697.

[118] Chen LD, Xi LL, Shi X, et al. Filled skutterudites: From single to multiple filling. Sci Sin-Phys Mech Astron 2011, 41: 706-728.

[119] Shiota Y, Ohishi Y, Matsuda M, et al. Improvement of thermoelectric property in Ce filled $\mathrm{Fe}_{3} \mathrm{Co}_{1} \mathrm{Sb}_{12}$ by $\mathrm{Sn}$ addition. J Alloys Compd 2020, 829: 154478.

[120] Yu J, Zhu WT, Zhao W, et al. Rapid fabrication of pure p-type filled skutterudites with enhanced thermoelectric properties via a reactive liquid-phase sintering. J Mater Sci 2020, 55: 7432-7440.

[121] Liu ZY, Zhu WT, Nie XL, et al. Effects of sintering temperature on microstructure and thermoelectric properties of Ce-filled $\mathrm{Fe}_{4} \mathrm{Sb}_{12}$ skutterudites. J Mater Sci: Mater Electron 2019, 30: 12493-12499.

[122] Dresselhaus M, Chen G, Tang M, et al. New directions for low-dimensional thermoelectric materials. Adv Mater 2007, 19: 1043-1053.

[123] Halperin WP. Quantum size effects in metal particles. Rev Mod Phys 1986, 58: 533-606.

[124] Bertini L, Stiewe C, Toprak M, et al. Nanostructured $\mathrm{Co}_{1-x} \mathrm{Ni}_{x} \mathrm{Sb}_{3}$ skutterudites: Synthesis, thermoelectric properties, and theoretical modeling. J Appl Phys 2003, 93:
$438-447$.

[125] Toprak M, Stiewe C, Platzek D, et al. The impact of nanostructuring on the thermal conductivity of thermoelectric $\mathrm{CoSb}_{3}$. Adv Funct Mater 2004, 14: 1189-1196.

[126] Yu BL, Tang XF, Qiong Q. Preparation an thermal transport properties of $\mathrm{CoSb}_{3}$ nano-compounds. Acta Physica Sinica 2004, 53: 3130.

[127] Stiewe C, Bertini L, Toprak M, et al. Nanostructured $\mathrm{Co}_{1-x} \mathrm{Ni}_{x}\left(\mathrm{Sb}_{1-y} \mathrm{Te}_{y}\right)_{3}$ skutterudites: Theoretical modeling, synthesis and thermoelectric properties. J Appl Phys 2005, 97: 044317

[128] Rao AM, Ji XH, Tritt TM. Properties of nanostructured one-dimensional and composite thermoelectric materials. MRS Bull 2006, 31: 218-223.

[129] Mi JL, Zhu TJ, Zhao XB, et al. Nanostructuring and thermoelectric properties of bulk skutterudite compound $\mathrm{CoSb}_{3}$. J Appl Phys 2007, 101: 054314.

[130] Alboni PN, Ji X, He J, et al. Synthesis and thermoelectric properties of "nano-engineered" $\mathrm{CoSb}_{3}$ skutterudite materials. J Electron Mater 2007, 36: 711-715.

[131] Chu Y, Tang XF, Zhao W, et al. Synthesis and growth of rodlike and spherical nanostructures $\mathrm{CoSb}_{3}$ via ethanol sol-gel method. Cryst Growth Des 2008, 8: 208-210.

[132] Li JQ, Feng XW, Sun WA, et al. Solvothermal synthesis of nano-sized skutterudite $\mathrm{Co}_{4-x} \mathrm{Fe}_{x} \mathrm{Sb}_{12}$ powders. Mater Chem Phys 2008, 112: 57-62.

[133] Mi JL, Zhao XB, Zhu TJ, et al. Nanosized La filled $\mathrm{CoSb}_{3}$ prepared by a solvothermal-annealing method. Mater Lett 2008, 62: 2363-2365.

[134] Lu PX, Wu F, Han HL, et al. Thermoelectric properties of rare earths filled $\mathrm{CoSb}_{3}$ based nanostructure skutterudite. J Alloys Compd 2010, 505: 255-258.

[135] Lan YC, Minnich AJ, Chen G, et al. Enhancement of thermoelectric figure-of-merit by a bulk nanostructuring approach. Adv Funct Mater 2010, 20: 357-376.

[136] Wen PF, Li P, Zhang QJ, et al. Effects of annealing on microstructure and thermoelectric properties of nanostructured $\mathrm{CoSb}_{3}$. J Electron Mater 2013, 42: 1443-1448.

[137] Khan A, Saleemi M, Johnsson M, et al. Fabrication, spark plasma consolidation, and thermoelectric evaluation of nanostructured $\mathrm{CoSb}_{3}$. J Alloys Compd 2014, 612: 293-300.

[138] Rogl G, Grytsiv A, Rogl P, et al. Nanostructuring of p- and n-type skutterudites reaching figures of merit of approximately 1.3 and 1.6, respectively. Acta Mater 2014, 76: 434-448.

[139] Kim SH, Kim MC, Kim MS, et al. Nanophase oxalate precursors of thermoelectric $\mathrm{CoSb}_{3}$ by controlled coprecipitation predicted by thermodynamic modeling. Adv Powder Technol 2016, 27: 773-778.

[140] Deng L, Ni J, Qin JM, et al. High pressure synthesis and thermoelectric properties of micro/nano structures $\mathrm{CoSb}_{3}$. J Solid State Chem 2017, 255: 129-132. 
[141] Zheng ZH, Wei M, Li F, et al. Improvement of power factor of $\mathrm{CoSb}_{3}$ thermoelectric thin films via microstructure optimization. Coatings 2017, 7: 205.

[142] Fu GS, Zuo L, Chen J, et al. Thermoelectric properties of DC-sputtered filled skutterudite thin film. J Appl Phys 2015, 117: 125304.

[143] Daniel MV, Lindorf M, Albrecht M. Thermoelectric properties of skutterudite $\mathrm{CoSb}_{3}$ thin films. J Appl Phys 2016, 120: 125306.

[144] Bala MJ, Gupta S, Srivastava SK, et al. Evolution of nanostructured single-phase $\mathrm{CoSb}_{3}$ thin films by low-energy ion beam induced mixing and their thermoelectric performance. Phys Chem Chem Phys 2017, 19: 24886-24895.

[145] Zheng ZH, Wei M, Luo JT, et al. An enhanced power factor via multilayer growth of Ag-doped skutterudite $\mathrm{CoSb}_{3}$ thin films. Inorg Chem Front 2018, 5: 1409-1414.

[146] Zheng ZH, Li F, Luo JT, et al. Thermoelectric properties and micro-structure characteristics of nano-sized $\mathrm{CoSb}_{3}$ thin films prefabricating by co-sputtering. J Alloys Compd 2018, 732: 958-962.

[147] Ahmed A, Han S. Effect of heating cycle on cobalt-antimonide-based thin films for high-temperature thermoelectric energy conversion applications. $J$ Alloys Compd 2019, 790: 577-586.

[148] Zhang Y, Fang ZH, Muhammed M, et al. The synthesis of superconducting bismuth compounds via oxalate coprecipitation. Phys C: Supercond 1989, 157: 108-114.

[149] Wang LG, Zhang Y, Muhammed M. Synthesis of nanophase oxalate precursors of $\mathrm{YBaCuO}$ superconductor by coprecipitation in microemulsions. J Mater Chem 1995, 5: $309-314$.

[150] Wang M, Zhang Y, Muhammed M. Paper VIII in M. Wang's doctoral thesis: Thermodynamic modelling of aqueous solutions and application in some fuctional materials synthesis. Royal Institute of Technology, Stockholm, 1999.

[151] Toprak M, Zhang Y, Muhammed M, et al. Chemical route to nano-engineered skutterudites. In: Proceedings of the 18th International Conference on Thermoelectrics, 1999: 382-385.

[152] Wang M, Zhang Y, Muhammed M. Synthesis and characterization of nano-engineered thermoelectric skutterudite via solution chemistry route. Nanostructured Mater 1999, 12: 237-240.

[153] Hopkins PE, Rakich PT, Olsson RH, et al. Origin of reduction in phonon thermal conductivity of microporous solids. Appl Phys Lett 2009, 95: 161902.

[154] Hsieh TY, Lin H, Hsieh TJ, et al. Thermal conductivity modeling of periodic porous silicon with aligned cylindrical pores. $J$ Appl Phys 2012, 111: 124329.

[155] Yu J, Zhao WY, Wei P, et al. Enhanced thermoelectric performance of $(\mathrm{Ba}, \mathrm{In})$ double-filled skutterudites via randomly arranged micropores. Appl Phys Lett 2014, 104: 142104.
[156] Fu LW, Yang JY, Peng JY, et al. Enhancement of thermoelectric properties of $\mathrm{Yb}$-filled skutterudites by an Ni-Induced "core-shell" structure. J Mater Chem A 2015, 3: $1010-1016$.

[157] Khan AU, Kobayashi K, Tang DM, et al. Nano-microporous skutterudites with $100 \%$ enhancement in ZT for high performance thermoelectricity. Nano Energy 2017, 31: $152-159$.

[158] Zhou ZX, Agne MT, Zhang QH, et al. Microstructure and composition engineering $\mathrm{Yb}$ single-filled $\mathrm{CoSb}_{3}$ for high thermoelectric and mechanical performances. $J$ Materiomics 2019, 5: 702-710.

[159] Liu ZH, Meng XF, Qin DD, et al. New insights into the role of dislocation engineering in N-type filled skutterudite $\mathrm{CoSb}_{3}$. J Mater Chem C 2019, 7: 13622-13631.

[160] Meng XF, Liu ZH, Cui B, et al. Grain boundary engineering for achieving high thermoelectric performance in n-type skutterudites. Adv Energy Mater 2017, 7: 1602582.

[161] Deng L, Li DN, Qin JM, et al. Effect of Pb filling and synthesis pressure regulation on the thermoelectric properties of $\mathrm{CoSb}_{3}$. Inorg Chem 2019, 58: 4033-4037.

[162] Yang HJ, Wen PF, Zhou XL, et al. Enhanced thermoelectric performance of Te-doped skutterudite with nano-microporous architecture. Scripta Mater 2019, 159: 68-71.

[163] Du Y, Cai KF, Chen S, et al. Investigation on indium-filled skutterudite materials prepared by combining hydrothermal synthesis and hot pressing. J Electron Mater 2011, 40: $1215-1220$

[164] Chen F, Liu RH, Yao Z, et al. Scanning laser melting for rapid and massive fabrication of filled skutterudites with high thermoelectric performance. J Mater Chem A 2018, 6: 6772-6779.

[165] Rogl G, Grytsiv A, Anbalagan R, et al. Direct SPD-processing to achieve high-ZT skutterudites. Acta Mater 2018, 159: 352-363.

[166] Li JF, Liu WS, Zhao LD, et al. High-performance nanostructured thermoelectric materials. NPG Asia Mater 2010, 2: 152-158.

[167] Zhao XY, Shi X, Chen LD, et al. Synthesis of $\mathrm{Yb}_{y} \mathrm{Co}_{4} \mathrm{Sb}_{12} / \mathrm{Yb}_{2} \mathrm{O}_{3}$ composites and their thermoelectric properties. Appl Phys Lett 2006, 89: 092121.

[168] Mi JL, Zhao XB, Zhu TJ, et al. Improved thermoelectric figure of merit in n-type $\mathrm{CoSb}_{3}$ based nanocomposites. Appl Phys Lett 2007, 91: 172116.

[169] Xiong Z, Chen XH, Huang XY, et al. High thermoelectric performance of $\mathrm{Yb}_{0.26} \mathrm{Co}_{4} \mathrm{Sb}_{12} / y \mathrm{GaSb}$ nanocomposites originating from scattering electrons of low energy. Acta Mater 2010, 58: 3995-4002.

[170] Zong PA, Chen XH, Zhu YW, et al. Construction of a

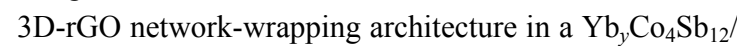
rGO composite for enhancing the thermoelectric performance. J Mater Chem A 2015, 3: 8643-8649.

[171] Gharleghi A, Hung PC, Lin FH, et al. Enhanced ZT of $\mathrm{In}_{x} \mathrm{Co}_{4} \mathrm{Sb}_{12}-\mathrm{InSb}$ nanocomposites fabricated by hydrothermal 
synthesis combined with solid-vapor reaction: A signature of phonon-glass and electron-crystal materials. ACS Appl Mater Interfaces 2016, 8: 35123-35131.

[172] Zong PA, Hanus R, Dylla M, et al. Skutterudite with graphene-modified grain-boundary complexion enhances $Z T$ enabling high-efficiency thermoelectric device. Energy Environ Sci 2017, 10: 183-191.

[173] Moure A, Rull-Bravo M, Abad B, et al. Thermoelectric Skutterudite/oxide nanocomposites: Effective decoupling of electrical and thermal conductivity by functional interfaces. Nano Energy 2017, 31: 393-402.

[174] Li WJ, Wang J, Xie YT, et al. Enhanced thermoelectric performance of $\mathrm{Yb}$-single-filled skutterudite by ultralow thermal conductivity. Chem Mater 2019, 31: 862-872.

[175] Eilertsen J, Rouvimov S, Subramanian MA. Rattler-seeded $\mathrm{InSb}$ nanoinclusions from metastable indium-filled $\mathrm{In}_{0.1} \mathrm{Co}_{4} \mathrm{Sb}_{12} \quad$ skutterudites for high-performance thermoelectrics. Acta Mater 2012, 60: 2178-2185.

[176] Eilertsen J, Surace Y, Balog S, et al. From occupied voids to nanoprecipitates: Synthesis of skutterudite nanocomposites in situ. Z Anorg Allg Chem 2015, 641: $1495-1502$.

[177] Qin DD, Wu HJ, Cai ST, et al. Enhanced thermoelectric and mechanical properties in $\mathrm{Yb}_{0.3} \mathrm{Co}_{4} \mathrm{Sb}_{12}$ with in situ formed CoSi nanoprecipitates. Adv Energy Mater 2019, 9: 1902435.

[178] Xiong Z, Chen XH, Zhao XY, et al. Effects of nano- $\mathrm{TiO}_{2}$ dispersion on the thermoelectric properties of filled-skutterudite $\mathrm{Ba}_{0.22} \mathrm{Co}_{4} \mathrm{Sb}_{12}$. Solid State Sci 2009, 11: $1612-1616$.

[179] Zhou XY, Wang GY, Zhang L, et al. Enhanced thermoelectric properties of Ba-filled skutterudites by grain size reduction and $\mathrm{Ag}$ nanoparticle inclusion. $J$ Mater Chem 2012, 22: 2958-2964.

[180] Chubilleau C, Lenoir B, Dauscher A, et al. Low temperature thermoelectric properties of $\mathrm{PbTe}-\mathrm{CoSb}_{3}$ composites. Intermetallics 2012, 22: 47-54.

[181] Duan B, Zhai PC, Wen PF, et al. Enhanced thermoelectric and mechanical properties of Te-substituted skutterudite via nano-TiN dispersion. Scripta Mater 2012, 67: $372-375$

[182] Chubilleau C, Lenoir B, Masschelein P, et al. Influence of $\mathrm{ZnO}$ nano-inclusions on the transport properties of the $\mathrm{CoSb}_{3}$ skutterudite. J Alloys Compd 2013, 554: 340-347.

[183] Fu LW, Yang JY, Xiao Y, et al. AgSbTe 2 nanoinclusion in $\mathrm{Yb}_{0.2} \mathrm{Co}_{4} \mathrm{Sb}_{12}$ for high performance thermoelectrics. Intermetallics 2013, 43: 79-84.

[184] Peng JY, Fu LW, Liu QZ, et al. A study of $\mathrm{Yb}_{0.2} \mathrm{Co}_{4} \mathrm{Sb}_{12}-\mathrm{AgSbTe}_{2}$ nanocomposites: Simultaneous enhancement of all three thermoelectric properties. $J$ Mater Chem A 2014, 2: 73-79.

[185] Chubilleau C, Lenoir B, Candolfi C, et al. Thermoelectric properties of $\mathrm{In}_{0.2} \mathrm{Co}_{4} \mathrm{Sb}_{12}$ skutterudites with embedded PbTe or ZnO nanoparticles. J Alloys Compd 2014, 589: 513-523.
[186] Battabyal M, Priyadarshini B, Sivaprahasam D, et al. The effect of $\mathrm{Cu}_{2} \mathrm{O}$ nanoparticle dispersion on the thermoelectric properties of $n$-type skutterudites. J Phys D: Appl Phys 2015, 48: 455309.

[187] Che P, Wang BB, Sun CY, et al. Influence of multi-walled carbon nanotubes on the thermoelectric properties of La-filled $\mathrm{CoSb}_{3}$ skutterudite composites. J Alloys Compd 2017, 695: 1908-1912.

[188] Rogl G, Grytsiv A, Failamani F, et al. Attempts to further enhance $Z T$ in skutterudites via nano-composites. $J$ Alloys Compd 2017, 695: 682-696.

[189] Ghosh S, Bisht A, Karati A, et al. Thermoelectric properties of $\mathrm{Co}_{4} \mathrm{Sb}_{12}$ with $\mathrm{Bi}_{2} \mathrm{Te}_{3}$ nanoinclusions. $J$ Phys: Condens Matter 2018, 30: 095701.

[190] Yadav S, Chaudhary S, Pandya DK. Incorporation of $\mathrm{MoS}_{2}$ nanosheets in $\mathrm{CoSb}_{3}$ matrix as an efficient novel strategy to enhance its thermoelectric performance. Appl Surf Sci 2018, 435: 1265-1272.

[191] He ZM, Stiewe C, Platzek D, et al. Nano $\mathrm{ZrO}_{2} / \mathrm{CoSb}_{3}$ composites with improved thermoelectric figure of merit. Nanotechnology 2007, 18: 235602.

[192] Alleno E, Chen L, Chubilleau C, et al. Thermal conductivity reduction in $\mathrm{CoSb}_{3}-\mathrm{CeO}_{2}$ nanocomposites. $J$ Electron Mater 2010, 39: 1966-1970.

[193] Ghosh S, Meledath Valiyaveettil S, Shankar G, et al. Enhanced thermoelectric properties of in-filled $\mathrm{Co}_{4} \mathrm{Sb}_{12}$ with InSb nanoinclusions. ACS Appl Energy Mater 2020, 3: 635-646.

[194] Harris IR. Hard magnets. Mater Sci Technol 1990, 6: 962-966.

[195] Liu ZY, Zhu JL, Wei P, et al. Candidate for magnetic doping agent and high-temperature thermoelectric performance enhancer: Hard magnetic M-type $\mathrm{BaFe}_{12} \mathrm{O}_{19}$ nanometer suspension. ACS Appl Mater Interfaces 2019, 11: 45875-45884.

[196] Rhoderick EH, Williams RH. Metal-Semiconductor Contacts, 2nd edn. Clarendon Press, 1988.

[197] Qin DD, Cui B, Zhu JB, et al. Enhanced thermoelectric and mechanical performance in n-type Yb-filled skutterudites through aluminum alloying. ACS Appl Mater Interfaces 2020, 12: 12930-12937.

[198] Zhou ZX, Li JL, Fan YC, et al. Uniform dispersion of SiC in Yb-filled skutterudite nanocomposites with high thermoelectric and mechanical performance. Scripta Mater 2019, 162: 166-171.

[199] Rogl G, Rogl P. How nanoparticles can change the figure of merit, $Z T$, and mechanical properties of skutterudites. Mater Today Phys 2017, 3: 48-69.

[200] Liu Z, Li Y, Duan B, Zhai PC. Experimental investigation on mechanical properties of nanocomposites skutterudite at different temperature. J Wuhan Univ Technol 2015, 37: $1-5$.

[201] Ravi V, Firdosy S, Caillat T, et al. Mechanical properties of thermoelectric skutterudites. AIP Conf Proc 2008, 969: 656-662. 
[202] Li H, Tang XF, Zhang QJ, et al. Rapid preparation method of bulk nanostructured $\mathrm{Yb}_{0.3} \mathrm{Co}_{4} \mathrm{Sb}_{12+y}$ compounds and their improved thermoelectric performance. Appl Phys Lett 2008, 93: 252109.

[203] Li H, Su XL, Tang XF, et al. Grain boundary engineering with nano-scale $\mathrm{InSb}$ producing high performance $\mathrm{In}_{x} \mathrm{Ce}_{y} \mathrm{Co}_{4} \mathrm{Sb}_{12+z}$ skutterudite thermoelectrics. J Materiomics 2017, 3: 273-279.

[204] Kogut I, Nichkalo S, Ohorodniichuk V, et al. Nanostructure features, phase relationships and thermoelectric properties of melt-spun and spark-plasma-sintered skutterudites. Acta Phys Polo A 2018, 133: 879-883.

[205] Yi HC, Moore JJ. Self-propagating high-temperature (combustion) synthesis (SHS) of powder-compacted materials. J Mater Sci 1990, 25: 1159-1168.

[206] Hendaoui A, Andasmas M, Amara A, et al. SHS of high-purity MAX compounds in the Ti-Al-C system. Int J Self-Propag High-Temp Synth 2008, 17: 129-135.

[207] Li BY, Rong LJ, Li YY, et al. Synthesis of porous Ni-Ti shape-memory alloys by self-propagating high-temperature synthesis: Reaction mechanism and anisotropy in pore structure. Acta Mater 2000, 48: 3895-3904.

[208] $\mathrm{Su}$ XL, Fu F, Yan YG, et al. Self-propagating high-temperature synthesis for compound thermoelectrics and new criterion for combustion processing. Nat Commun 2014, 5: 4908.

[209] Liang T, Su XL, Yan YG, et al. Ultra-fast synthesis and thermoelectric properties of Te doped skutterudites. $J$ Mater Chem A 2014, 2: 17914-17918.

[210] Li XH, Zhang Q, Kang YL, et al. High pressure synthesized Ca-filled $\mathrm{CoSb}_{3}$ skutterudites with enhanced thermoelectric properties. J Alloys Compd 2016, 677: 61-65.

[211] Kang YL, Yu FR, Chen C, et al. High pressure synthesis and thermoelectric properties of Ba-filled $\mathrm{CoSb}_{3}$ skutterudites. J Mater Sci: Mater Electron 2017, 28: 8771-8776.

[212] Xu ZJ, Wu HJ, Zhu TJ, et al. Attaining high mid-temperature performance in $(\mathrm{Bi}, \mathrm{Sb})_{2} \mathrm{Te}_{3}$ thermoelectric materials via synergistic optimization. NPG Asia Mater 2016, 8: e302.

[213] Xie DW, Xu JT, Liu GQ, et al. Synergistic optimization of thermoelectric performance in P-type $\mathrm{Bi}_{0.48} \mathrm{Sb}_{1.52} \mathrm{Te}_{3} /$ graphene composite. Energies 2016, 9: 236.

[214] Xiao C, Li Z, Xie Y. Synergistic optimization of electrical and thermal transport properties in chalcogenides thermoelectric materials. Chin J Inorg Chem 2014, 30: 10-19.

[215] Zhu TJ, Liu YT, Fu CG, et al. Compromise and synergy in high-efficiency thermoelectric materials. Adv Mater 2017, 29: 1605884 .

[216] Xiao C, Xu J, Li K, et al. Superionic phase transition in silver chalcogenide nanocrystals realizing optimized thermoelectric performance. J Am Chem Soc 2012, 134: 4287-4293.

[217] Xiao C, Xu J, Cao BX, et al. Solid-solutioned homojunction nanoplates with disordered lattice: A promising approach toward "phonon glass electron crystal" thermoelectric materials. J Am Chem Soc 2012, 134: 7971-7977.

[218] Yao WY, Yang DF, Yan YC, et al. Synergistic strategy to enhance the thermoelectric properties of $\mathrm{CoSbS}_{1-x} \mathrm{Se}_{x}$ compounds via solid solution. ACS Appl Mater Interfaces 2017, 9: 10595-10601.

[219] Zhao WY, Wei P, Zhang QJ, et al. Multi-localization transport behaviour in bulk thermoelectric materials. Nat Commun 2015, 6: 6197.

[220] Hendricks T, Choate WT. Engineering scoping study of thermoelectric generator systems for industrial waste heat recovery. Technical Report. United States: Office of Scientific and Technical Information, 2006.

[221] Goldsmid H. Electronic Refrigeration. London: Pion Limited, 1986.

[222] Zhang QH, Liao JC, Tang YS, et al. Realizing a thermoelectric conversion efficiency of $12 \%$ in bismuth telluride/skutterudite segmented modules through full-parameter optimization and energy-loss minimized integration. Energy Environ Sci 2017, 10: 956-963.

[223] Zhang QH, Huang XY, Bai SQ, et al. Thermoelectric devices for power generation: Recent progress and future challenges. Adv Eng Mater 2016, 18: 194-213.

[224] Zhao DG, Li XY, He L, et al. Interfacial evolution behavior and reliability evaluation of $\mathrm{CoSb}_{3} / \mathrm{Ti} / \mathrm{Mo}-\mathrm{Cu}$ thermoelectric joints during accelerated thermal aging. $J$ Alloys Compd 2009, 477: 425-431.

[225] Godlewska E, Zawadzka K, Mars K, et al. Protective properties of magnetron-sputtered $\mathrm{Cr}-\mathrm{Si}$ layers on $\mathrm{CoSb}_{3}$. Oxid Met 2010, 74: 205-213.

[226] Liu G, Zhao WY, Zhou HY, et al. Design and optimization of gradient interface of $\mathrm{Ba}_{0.4} \mathrm{In}_{0.4} \mathrm{Co}_{4} \mathrm{Sb}_{12} / \mathrm{Bi}_{2} \mathrm{Te}_{2.7} \mathrm{Se}_{0.3}$ thermoelectric materials. J Electron Mater 2012, 41: 1376-1382.

[227] Gu M, Xia XG, Li XY, et al. Microstructural evolution of the interfacial layer in the $\mathrm{Ti}-\mathrm{Al} / \mathrm{Yb}_{0.6} \mathrm{Co}_{4} \mathrm{Sb}_{12}$ thermoelectric joints at high temperature. J Alloys Compd 2014, 610: 665-670.

[228] Chen WA, Chen SW, Tseng SM, et al. Interfacial reactions in $\mathrm{Ni} / \mathrm{CoSb}_{3}$ couples at $450{ }^{\circ} \mathrm{C} . J$ Alloys Compd $2015, \mathbf{6 3 2}$ : 500-504.

[229] Bae KH, Choi SM, Kim KH, et al. Power-generation characteristics after vibration and thermal stresses of thermoelectric unicouples with $\mathrm{CoSb}_{3} / \mathrm{Ti} / \mathrm{Mo}(\mathrm{Cu})$ interfaces. J Electron Mater 2015, 44: 2124-2131.

[230] Gu M, Xia XG, Huang XY, et al. Study on the interfacial stability of p-type $\mathrm{Ti} / \mathrm{Ce}_{y} \mathrm{Fe}_{x} \mathrm{Co}_{4-x} \mathrm{Sb}_{12}$ thermoelectric joints at high temperature. $J$ Alloys Compd 2016, 671: 238-244.

[231] Li GD, Hao SQ, Aydemir U, et al. Structure and failure mechanism of the thermoelectric $\mathrm{CoSb}_{3} / \mathrm{TiCoSb}$ interface. ACS Appl Mater Interfaces 2016, 8: 31968-31977.

[232] Zhao DG, Wu D, Ning JA, et al. Protective properties of 
various coatings on $\mathrm{CoSb}_{3}$ thermoelectric material. $J$ Electron Mater 2017, 46: 3036-3042.

[233] Chen SW, Chu AH, Wong DSH. Interfacial reactions at the joints of $\mathrm{CoSb}_{3}$-based thermoelectric devices. $J$ Alloys Compd 2017, 699: 448-454.

[234] Bao X, Gu M, Zhang QH, et al. Protective properties of electrochemically deposited Al-based coatings on $\mathrm{Yb}_{0.3} \mathrm{Co}_{4} \mathrm{Sb}_{12}$ skutterudite. J Electron Mater 2019, 48: $5523-5531$.

[235] Zybala R, Wojciechowski K, Schmidt M, et al. Junctions and diffusion barriers for high temperature thermoelectric modules. Mater Ceram Ceram Mater 2010, 62: 481-485.

[236] Zhang QH, Zhou ZX, Dylla M, et al. Realizing high-performance thermoelectric power generation through grain boundary engineering of skutterudite-based nanocomposites. Nano Energy 2017, 41: 501-510.

[237] Park SH, Jin Y, Cha J, et al. High-power-density skutterudite-based thermoelectric modules with ultralow contact resistivity using $\mathrm{Fe}-\mathrm{Ni}$ metallization layers. $A C S$ Appl Energy Mater 2018, 1: 1603-1611.

[238] Saber HH, El-Genk MS, Caillat T. Tests results of skutterudite based thermoelectric unicouples. Energy Convers Manag 2007, 48: 555-567.

[239] Choi SM, Kim KH, Jeong SM, et al. A resistance ratio analysis for $\mathrm{CoSb}_{3}$-based thermoelectric unicouples. $J$ Electron Mater 2012, 41: 1004-1010.

[240] Muto A, Yang J, Poudel B, et al. Skutterudite unicouple characterization for energy harvesting applications. $A d v$ Energy Mater 2013, 3: 245-251.

[241] Li WJ, Stokes D, Poudel B, et al. High-efficiency skutterudite modules at a low temperature gradient. Energies 2019, 12: 4292.

[242] Zhao DG, Tian CW, Tang SQ, et al. Fabrication of a $\mathrm{CoSb}_{3}$-based thermoelectric module. Mater Sci Semicond Process 2010, 13: 221-224.

[243] Katsuyama S, Yamakawa W, Matsumura Y, et al. Fabrication of thermoelectric module consisting of rare-earth-filled skutterudite compounds and evaluation of its power generation performance in air. $J$ Electron Mater 2019, 48: 5257-5263.

[244] Nie G, Suzuki S, Tomida T, et al. Performance of skutterudite-based modules. J Electron Mater 2017, 46:
2640-2644.

[245] Zong PA, Hanus R, Dylla M, et al. Skutterudite with graphene-modified grain-boundary complexion enhances ZT enabling high-efficiency thermoelectric device. Energy Environ Sci 2017, 10: 183-191.

[246] Salvador JR, Cho JY, Ye ZX, et al. Thermal to electrical energy conversion of skutterudite-based thermoelectric modules. J Electron Mater 2013, 42: 1389-1399.

[247] Geng HY, Ochi T, Suzuki S, et al. Thermoelectric properties of multifilled skutterudites with $\mathrm{La}$ as the main filler. J Electron Mater 2013, 42: 1999-2005.

[248] Salvador JR, Cho JY, Ye ZX, et al. Conversion efficiency of skutterudite-based thermoelectric modules. Phys Chem Chem Phys 2014, 16: 12510-12520.

[249] Jang H, Kim JB, Stanley A, et al. Fabrication of skutterudite-based tubular thermoelectric generator. Energies 2020, 13: 1106.

[250] Yusuf A, Ballikaya S. Modelling a segmented skutterudite-based thermoelectric generator to achieve maximum conversion efficiency. Appl Sci 2020, 10: 408.

[251] Dong HL, Li XY, Huang XY, et al. Improved oxidation resistance of thermoelectric skutterudites coated with composite glass. Ceram Int 2013, 39: 4551-4557.

[252] Xia XG, Huang XY, Li XY, et al. Preparation and structural evolution of $\mathrm{Mo} / \mathrm{SiO}_{x}$ protective coating on $\mathrm{CoSb}_{3}$-based filled skutterudite thermoelectric material. $J$ Alloys Compd 2014, 604: 94-99.

Open Access This article is licensed under a Creative Commons Attribution 4.0 International License, which permits use, sharing, adaptation, distribution and reproduction in any medium or format, as long as you give appropriate credit to the original author(s) and the source, provide a link to the Creative Commons licence, and indicate if changes were made.

The images or other third party material in this article are included in the article's Creative Commons licence, unless indicated otherwise in a credit line to the material. If material is not included in the article's Creative Commons licence and your intended use is not permitted by statutory regulation or exceeds the permitted use, you will need to obtain permission directly from the copyright holder.

To view a copy of this licence, visit http://creativecommons.org/licenses/by/4.0/. 